\title{
The Merits of Integrating Accelerated Experiential Dynamic Psychotherapy and Cultural Competence Strategies in the Treatment of Relational Trauma: The Case of "Rosa"
}

\author{
NICOLE VIGODA GONZALEZ ${ }^{\mathrm{a}, \mathrm{b}, \mathrm{c}}$ \\ ${ }^{\text {a }}$ Counseling and Psychological Services, Columbia University \\ ${ }^{\mathrm{b}}$ Correspondence regarding this article should be sent to Nicole Vigoda Gonzales, Counseling and \\ Psychological Services, Columbia University, Alfred Lerner Hall, 5th and 8th Floors, Mail Code 2606, \\ 2920 Broadway, New York, NY 10027 \\ ${ }^{\mathrm{c}}$ Note: This article is a reformatted and edited version of my dissertation (Vigoda Gonzales, 2017). \\ Email: nivigo@gmail.com
}

\begin{abstract}
The psychological sequelae of prolonged and repeated exposure to relational trauma can manifest into a challenging clinical picture typically known as Complex PTSD. Accelerated Experiential Dynamic Psychotherapy (AEDP) is a multimodal and integrative model particularly designed to address attachment disturbances and extreme forms of affective avoidance and dysregulation commonly seen in survivors of relational trauma. Conducting this treatment in a language that is not the patient's native tongue may interfere with emotional processing, a key component of AEDP. The purpose of this study is twofold. First, it aims to examine the benefits of experiential and attachment-based models for the treatment of "Rosa," a bilingual woman and survivor of relational trauma, who presented to treatment with depressive and Complex PTSDlike symptom. Second, the study explores whether actively incorporating Rosa's bilingualism and ethnic identity into the treatment enhanced her capacity for emotional processing and other related aspects of AEDP. This exploration constitutes an ideal avenue for documenting the clinical challenges one may encounter in doing psychotherapy with bilingual trauma survivors. For in this type of therapy, the affective processing of traumatic memories can be lost in translation. This requires the creation of an individualized treatment plan that can address these barriers, amplifying the emergence of relational safety and ultimately facilitating the patient's new experience of core state (Fosha \& Yeung, 2006), an integrated state of clarity, ease, and self-compassion.
\end{abstract}

Key words: Accelerated Experiential Dynamic Therapy (AEDP); post-traumatic stress disorder (PTSD); the role of bilingualism; the role if biculturalism; ethnic/cultural matching; therapeutic alliance; systematic case studies; clinical case studies; emotional change process; corrective emotional experience 
Competence Strategies in the Treatment of Relational Trauma: The Case of "Rosa"

N.Vigoda Gonzales

Pragmatic Case Studies in Psychotherapy, http://pcsp.libraries.rutgers.edu

Volume 14, Module 1, Article 1, pp. 1-57, 09-12-18 [copyright by author]

\section{CASE CONTEXT AND METHOD}

\section{The Rationale for Selecting this Particular Client for Study}

The present study closely examines the suitability of Accelerated Experiential Dynamic Psychotherapy for the treatment of relational trauma, as well as the treatment enhancing effects of incorporating a culturally sensitive focus into this particular therapeutic approach. The psychological sequelae of prolonged and repeated exposure to relational trauma can be quite profound, manifesting into a challenging clinical picture that has been labeled in the literature as Complex PTSD (Herman, 1992a, 1992b). Accelerated Experiential Dynamic Psychotherapy is an attachment-focused and affect-focused experiential treatment approach particularly designed to address Complex PTSD factors including attachment/interpersonal disturbances, emotional dysregulation, dissociation and identity diffusion (Gleiser, Ford, \& Fosha, 2008). A crucial element of AEDP is emotional processing, which involves fully experiencing core affects like grief, pain, anger, and compassion for self, with the fundamental goal of helping the patient process emotion to completion, that is, to experience and master them (Fosha 2004, 2006). Conducting treatment in a language that is not the patient's native tongue may interfere with emotional processing. This study aims to examine the impact of bilingualism and ethnic matching on this and other elements of the AEDP-informed treatment, and the effects of actively incorporating these cultural aspects into the treatment.

The focal case selected for analysis in this study, hereafter referred to by the pseudonym "Rosa", clearly illustrates the challenges mentioned above, and allows for their close examination and implications for clinical treatment. Rosa, a 63-year old Hispanic woman who was a survivor of repeated familial abuse and neglect, presented with depression and many of the Complex PTSD-like symptoms described above. Moreover, her ethnic and racial identity was the target of much of the abuse and neglect received within her family. Despite being fully bilingual, her native tongue was Spanish, and early into the treatment it became evident that much of the affective processing of traumatic experiences was lost in translation. Presenting the course of treatment with Rosa constitutes an ideal avenue for exploring the process by which an individualized treatment plan was created in an effort to account for the complexity and uniqueness of this case, and the course of treatment that unfolded.

\section{The Clinical Setting in Which the Case Took Place}

The setting was a Clinic within the community. The fee was set according to Rosa's financial income. At the time of therapy, I was an advanced doctoral clinical psychology student, and was taking a course in short-term dynamic therapy. As part of the course I was supervised after each therapy session by Dr. Karen Skean, Psy.D., a senior clinical psychologist trained in Accelerated Experiential Dynamic Psychotherapy and with in-depth theoretical and clinical experience in the treatment of survivors of relational trauma. This case study constituted my doctoral dissertation, and the research design was thus approved by the Institutional Review Committee of my university. The treatment consisted of 23 sessions over a period of seven months, and an additional follow-up session three moths after termination. 
Rosa's case was assigned to me as the applied portion of a course in short-term dynamic psychotherapy. Due to the nature of Rosa's relational trauma history and her complex clinical presentation, I opted to use a short-term dynamic approach designed to address the attachment disturbances and insufficient internal affect regulation skills associated with Complex PTSD. As such, the treatment was heavily influenced by experiential and attachment-based models, particularly AEDP, while simultaneously incorporating cultural competence principles to account for the salient role of the patient's bilingualism and ethnic identity.

\section{The Methodological Strategies Employed for Enhancing the Rigor of the Study}

All sessions were recorded on DVD and subsequently reviewed by the therapist and supervisor of the case, who provided guidance and insight. Our supervisions were held weekly for the purpose of assessing the treatment's progress and the patient's symptomatology. The case was further reviewed in two presentations to other advanced doctoral students as part of the short-term dynamic psychotherapy course, which provided a fruitful space for discussion related to the progress of the case. All of the above were instrumental in the development of an individualized treatment plan and its ongoing revision. Finally, three quantitative measures were used to assess the patient's symptoms at the start and end of treatment. These measures and the results are discussed below in Chapter IV on assessment and Chapter VIII on outcome.

\section{Sources of Data Available Concerning the Client}

Prior to the beginning of treatment, no information about the patient was available to me as the therapist, beyond the results gathered at an initial phone screening done by one of the Clinic's coordinators.

\section{Confidentiality}

Confidentiality is maintained within this document by including no information by which the patient can be recognized. In other words, all information has been de-identified and/or further disguised in order to protect the patient's identity. That said, the detailed and rich nature by which the case is described maintains an authentic and accurate picture of the clinical process of this patient's treatment.

\section{THE CLIENT}

At the onset of treatment Rosa was a bilingual, 63-year-old, divorced, Hispanic woman living alone, who had retired 4 years ago after working as a school counselor for more than 2 decades. She was highly educated and articulate, and in spite her full command of English, she would occasionally use words in Spanish that seemed to carry emotional meaning. Immediately after retirement, Rosa had taken care of her ailing mother until her death in 2012. She presented to the Clinic complaining of overwhelming anxiety and depression in the context of her son's worsening alcohol use, which was triggering disturbing memories about her childhood. Additionally, Rosa acknowledged feeling depressed and anxious since the death of her mother, after which existing conflict with her siblings exacerbated and she became increasingly isolated. 
She reported difficulty sleeping, disturbing nightmares, and intense feelings of sadness, anger and guilt, especially when recalling events about her childhood and her relationship with her siblings.

Rosa met DSM-IV-TR criteria for Major Depressive Disorder, severe, recurrent; and Anxiety Disorder NOS. She also endorsed many of the symptoms of Complex PTSD (Herman, 1992b), including attachment disturbances, difficulty regulating extreme emotions, profoundly negative beliefs about herself and relationships, and entrenched defenses. A survivor of repeated familial abuse, Rosa made explicit her wish to abstain from revisiting her traumatic childhood, stating that she wanted to put that behind.her. As she began to become more open, the trauma became the focus of the treatment. Prior to our work together, Rosa had been in therapy twice but had never talked about her history of relational trauma. Our treatment would ultimately last 23 sessions over a period of seven months, and an additional follow-up session three months after termination.

\section{GUIDING CONCEPTION, WITH RESEARCH AND CLINICAL EXPERIENCE SUPPORT}

\section{Introduction}

The guiding conception underlying Rosa's case formulation and treatment plan addresses two major areas fundamentally relevant to this case: (1) the benefits of experiential and attachment-based models for the treatment of relational trauma sequelae, particularly Complex PTSD-like symptoms; and (2) the potential treatment enhancing effects of incorporating aspects of the patient's cultural identity into the treatment, namely her bilingualism and ethnic identity. I will start by providing empirical research and theory, which support each of these areas, and I will conclude by elaborating on the rationale for incorporating the two. Rosa's complex clinical picture and her initial response to interventions were crucial in selecting AEDP as the best shortterm psychodynamic treatment approach, and the active incorporation of a culturally sensitive lens served to enhance the effects of this particular treatment approach.

\section{The Nature of Complex Post-Traumatic Stress Disorder}

The effects of childhood maltreatment can be profound and lasting. Abuse and neglect not only are potentially traumatic stressors, but also may negatively interfere with the optimal development of biological, psychological, and interpersonal regulatory capacities (Ford, 2005). Ample empirical and clinical findings strongly support the assumption that chronic exposure to such "developmentally adverse interpersonal trauma" (DAIT; Ford, 2005), which I will refer to here as "relational trauma," (Schore, 2001) is a predictor of a syndrome labeled "Complex PostTraumatic Stress Disorder" ("Complex PTSD”; Herman, 1992b; Cloitre, Gavert, Brewin, Bryant, \& Maercker, 2013; Cloitre, Gavert, Weiss, Carlson, \& Bryant, 2014), with severe and complex forms of psychological disturbances (Cloitre, Stolbach, Herman, van der Kolk, Pynoos, Wang, \& Petkova, 2009; van der Kolk, Roth, Pelcovitz, Sunday, \& Spinazzola, 2005; Briere, Kaltman \& Green, 2008). Specifically, as shown in Table 1, Complex PTSD includes not only PostTraumatic Stress Disorder (PTSD) symptoms, but also disturbances predominantly in affective 
and interpersonal self-regulatory capacities (Cloitre et al, 2009; Jonkman, Verlinden, Bolle, Boer, \& Lindauer, 2013), such as difficulties with extreme emotion states, dissociative symptoms, attachment disturbances, medically unexplained bodily complaints, and profoundly negative beliefs about self and others.

Complex PTSD is a controversial syndrome that has not been formally recognized as a DSM diagnosis in and of itself. The idea that Complex PTSD is the equivalent of Borderline Personality Disorder (BPD), or an amalgam of PTSD and BPD, has been discussed in the literature (Herman, 1992b; Cloitre et al., 2013; Cloitre et al., 2014). Herman (1992b) suggested that this, and other disorders (i.e., somatization disorder, and multiple personality disorder), may be better understood as variants of Complex Post-Traumatic Stress Disorder, with all of them sharing a common denominator: a history of childhood trauma. More recently, the World Health Organization (WHO) Working Group on the Classification of Stress-Related Disorders has proposed the inclusion of Complex PTSD as a new diagnosis in ICD-11 (see Table 1; (Maercker, Brewin, Bryant, Cloitre, Van Ommeren, et al., 2013).

In support of this, Cloitre and colleagues (2014) have argued that the key clinical features of Complex PTSD and BPD differ significantly. In fact, findings from their empirical study suggest that Complex PTSD and BPD are distinct diagnostic categories with different symptom profiles, and therefore different treatment implications. According to these results, BPD is characterized by fears of abandonment, an unstable sense of self, unstable relationships characterized by chaotic engagement with others, and impulsive and self-harming behaviors. In contrast, in Complex PTSD self-injurious behaviors are minimally endorsed, the self-concept is likely to be consistently negative and relational difficulties concern mostly avoidance and a sense of alienation. Finally, while emotion regulation difficulties are common to both disorders, in CPTSD the expression of such difficulties predominantly include emotional sensitivity, reactive anger, and poor coping responses, while in BPD these are mostly characterized by suicidal gestures and self-injurious behaviors (Cloitre et al., 2014).

The presence of Complex PTSD symptoms has been shown to be a negative prognostic indicator of both PTSD treatment outcome and behavioral disturbances in diverse clinical samples (van der Kolk et al., 2005). Disturbances in attachment become one of the most difficult barriers to the establishment of a therapeutic alliance with survivors of relational trauma, who have not learned to "join" safely with a caregiver without becoming enmeshed or detached, thus becoming both rejecting and rejected (Ford et al., 2005).

In addition to this, extreme forms of avoidance, as well as severe forms of emotion dysregulation, turn the treatment of relational trauma sequelae into anything but straightforward. The aftermath of relational trauma is so profound that it warrants the development and implementation of multimodal and integrative psychotherapies that do justice to its complex clinical presentation (Gleiser et al., 2008; Schnyder, 2005). Moreover, given the fact that relational trauma occurs at the hands of attachment figures, treatment of such disorders should seek to heal attachment-related injuries and maladaptive interpersonal patterns that are sometimes more functionally impairing than PTSD symptoms (Cloitre et al., 2005; Herman, 1992a). 
Competence Strategies in the Treatment of Relational Trauma: The Case of "Rosa"

N.Vigoda Gonzales

Pragmatic Case Studies in Psychotherapy, http://pcsp.libraries.rutgers.edu

Volume 14, Module 1, Article 1, pp. 1-57, 09-12-18 [copyright by author]

\section{Accelerated Experiential Dynamic Psychotherapy (AEDP) and Complex PTSD}

From this point of view, Diana Fosha's (2000) Accelerated Experiential Dynamic Psychotherapy (AEDP) has been presented as a " 'multimodal, integrative' model well-equipped to address the clinical complexities of Complex PTSD” (Gleiser et al., 2008, p. 341). Fosha's theory was initially rooted in Davanloo's (1980) Intensive Short-Term Dynamic Psychotherapy (ISTDP), which includes a confrontational path to affective exploration. However, in contrast, Fosha's theory developed a non-confrontational path that is strongly influenced by attachment and object relations theories (i.e., Winnnicott, 1965; Bowlby, 1973, 1980, 1982; Ainsworth et al., 1978). These latter theories are experiential psychotherapies grounded both in client-centered, existential, and Gestalt traditions, and in research on affective neuroscience (i.e., Damasio, 1999; Panksepp, 1998; Schore, 1994). AEDP is grounded in the assumption that attachment security is a transformative experience that potentiates deep and lasting psychological change, by organically evoking the painful experiences of the original relational trauma and facilitating the processing of adaptive emotions to completion (Fosha, 2000; Gleiser et al., 2008; Russell \& Fosha, 2008; Lipton and Fosha, 2011). Indeed, Lipton and Fosha (2011) write,

For people with histories of relational trauma, it is the very attachment experience itself - the experiential cocreation of safety and trust - that both frames and comprises the specific, detailed, moment-to-moment coloration of the therapeutic endeavor. Attachment phenomena remain in focus from beginning to end (p. 276).

Fosha's strong focus on attachment and affective exploration is based on the idea that survivors of relational trauma have been chronically exposed to the being alone with intense and overwhelming emotional experiences. As children, these survivors not only endured physical, emotional, and sexual abuse; most of them were also victims of what Fosha (2000) has identified as caregiver errors of omission and commission in which a child's expression of his/her feelings or attempts to seek help regulating affect are frequently met with withdrawal, rejection, and contempt (Fosha 2000; Gleiser et al., 2008). Consequently, the child learns that certain emotions (which are usually adaptive) must be either disowned or silently endured in order to preserve the relationship with the caregiver (Fosha, 2000), and thus insecure attachment patterns develop. As adults, these survivors of relational trauma continue to be plagued by intense and powerful unmet needs for closeness, comfort, security, and understanding, and yet they remain submerged in these "terrifying internal worlds of unbearable, dysregulated, and often dissociated feelings" (Gleiser et al., 2008, p. 347). Such “unbearable states of aloneness” (Fosha, 2002, italics hers) are precisely what AEDP seeks to remedy, so that the path for the patient's natural resilience is cleared and made open, ultimately facilitating the development of alternate internal working models (Gleiser et al., 2008; Lipton \& Fosha, 2011).

\section{AEDP's Strategies for Undoing Aloneness}

How does the AEDP-informed therapist work toward achieving this seemingly monumental task? Fosha (2000, 2002a, 2002b, 2003, 2004, 2006) suggests that the key to healing the wounds of relational trauma consists of co-creating new emotional and relational experiences within the therapeutic dyad. 
Competence Strategies in the Treatment of Relational Trauma: The Case of "Rosa"

N.Vigoda Gonzales

Pragmatic Case Studies in Psychotherapy, http://pcsp.libraries.rutgers.edu

Volume 14, Module 1, Article 1, pp. 1-57, 09-12-18 [copyright by author]

In AEDP, attachment-based strategies are used to facilitate new relational experiences. Fosha (2000, 2002) speaks about attachment-based strategies as embodying Bowlby's (1982) core principle, namely, that secure attachment promotes an expanded range of exploration. This principle profoundly influences the stance of the AEDP therapist, who strives to be perceived as committed and trustworthy in an effort to boost the patient's courage and capacity to experientially explore painful traumatic memories (Gleiser et al., 2008). Thus, the therapist leads as a stronger and wiser other (Bowlby, 1982), and also follows by being emotionally connected and responsive (Ainsworth et al., 1978). Fosha (2002b) strongly encourages the AEDP therapist to be affirming, emotionally engaged, explicitly empathetic, and candid, in other words, a "true other." By "being" this way, the therapist is modeling affective competence, which means "feeling and dealing" while relating to a safe other (Fosha, 2000). Ultimately, this is the goal of treatment.

However, AEDP posits that it is not sufficient that attachment operate implicitly (Fosha, 2000; Gleiser et al., 2008; Lipton \& Fosha, 2011). The patient's experience of attachment needs to remain a focus of treatment. Practically, what this means is that the therapist gently and carefully leads the patient into a collaborative exploration of whether and how the patient feels cared about, helped, and/or understood by the therapist (Fosha 2000; Gleiser et al., 2008; Russell $\&$ Fosha, 2008). The dances between approach and withdrawal, connection and rejection, or any other attempt to distance oneself in the therapeutic dyad, are carefully reflected upon, thereby increasing awareness and making connection a "shared and explicit goal" (Gleiser et al., 2008, p. 347). Thus, these repeated cycles of realization, feeling, and meta-processing of the attachment experience enable the patient to increasingly experience the therapeutic relationship as a source of safety, euthymia, and increasing confidence in his/her ability to manage intense emotion (Gleiser et al., 2008).

While the attachment-based strategies described above are used to facilitate new relational experiences, emotion-processing strategies are used to facilitate new emotional experiences (Gleiser et al., 2008). Fosha borrows from Greenberg and Safran's (1989, p. 20) conceptualization of emotions as an "orienting system that provides the organism with adaptive information." Emotions are understood as having a purpose, that is, a function, and processing emotions means getting in touch with them so that we can act accordingly on behalf of the self (Fosha, 2004, 2006). The modus operandi of survivors of trauma is to overregulate or avoid core emotions, which are understood in AEDP as "bearing the seeds of healing" (Gleiser et al., 2008). Typically, they perceive them as being "too overwhelming," "too painful," or simply something to "stay away from." The purpose in AEDP is to shift the patient's perspective to one of competence, in which emotions are seen as "being there for a reason." (Gleiser et al., 2008). Ultimately, the goal is to accompany the patient through the processing of adaptive emotion to completion in the context of a secure therapeutic relationship (Fosha, 2000, 2004; Gleiser et al., 2008; Lipton \& Fosha, 2011).

In AEDP this process involves three States and two State Transformations (Fosha, 2000, 2007; Gleiser et al., 2008). State 1, namely symptoms, stress, and distress, consists in helping the patient identify and work through the defense mechanism and/or inhibiting affect (consisting of shame, anxiety, fear, despair, helplessness, panic) that get in the way of somatically experiencing 
emotions, and thus give way to the first glimmers of core affect (consisting of anger, grief, pain, compassion for the self, longing for connection, joy, sadness). In AEDP, core affect refers to emotional, visceral experiences that are free of defense and appropriate to the context. It is a clinical phenomenon that constitutes a state wherein profound opportunities for deep, rapid, and transformative therapeutic work exists (Fosha, 2000). Inhibiting affect like anxiety and shame, on the other hand, interfere with this core emotional experience, by acting as a red-signal that alerts the individual to stay away from those core feelings (Fosha, 2004). The transition to State 2, the experiencing and processing of core affective experience, constitutes the First State Transformation.

In the state of core affect, the patient feels his/her emotions associated with the relational trauma more intensely and authentically. With guidance from the AEDP therapist, these emotions are regulated, processed, and worked through to completion. Ideally, as patient and therapist together reflect upon this new emotional experience, positive affect (e.g., hope, mastery, and self-compassion) is released. Once again the patient is guided through the metatherapeutic processing of the successful experience of completing work on the second affective wave, and the patient then reaches State 3, or core state.

Although most experiential psychotherapies also focus on emotion processing, what makes AEDP unique in this area is the addition of this extra phase of work in the context of a securely attached relationship (Gleiser et al., 2008; Lipton \& Fosha, 2011). The transition from core affect to core state is the Second State Transformation. In core state, called the "crown jewel of AEDP" by Fosha and Yeung (2006), the patient feels calm, clear, integrated, and selfcompassionate. It is in this state that resilience, commonly compromised in the presence of Complex PTSD symptomatology, naturally emerges. Thus, as Gleiser and colleagues (2008) eloquently write "the treatment of Complex PTSD with AEDP not only strives for symptomatic relief but actually addresses the havoc that trauma wreaks at the core, attending to not just function, but also joy, aliveness, relational connection, and effectiveness" (p. 350).

\section{Bilingualism and Ethnic Matching}

The second area relevant to the guiding conception underlying Rosa's case is the role of bilingualism and ethnic identity in affective processing and exploration, particularly the potential treatment-enhancing effects of incorporating these elements actively into the therapy. In the case of Rosa, these two aspects of cultural identity appeared to play an important role in her ability to process emotions fully and recall traumatic memories, a fundamental aspect of any AEDPinformed treatment.

\section{Clinical Implications of Working with Bilingual Patients}

Encounters in therapy where clinician and client have access to more than one language are becoming increasingly common (Byford, 2015). Despite the limited research on how language shapes the therapeutic relationship and discourse (Kokaliari, Catanzarite, \& Berzoff, 2013), historically bilingualism has been recognized as an important variable in psychotherapy and numerous case studies have examined this closely. An important issue identified through 
Competence Strategies in the Treatment of Relational Trauma: The Case of "Rosa"

N.Vigoda Gonzales

Pragmatic Case Studies in Psychotherapy, http://pcsp.libraries.rutgers.edu

Volume 14, Module 1, Article 1, pp. 1-57, 09-12-18 [copyright by author]

several of these case studies is the impact of language choice (i.e., first vs. second language) on the capacity to access and/or fully experience emotionally-laden material and memories.

In early contributions, Buxbaum (1949) and Greenson (1950) presented two cases of their respective work with bilingual women who spoke English as a second language and German as their native tongue. Buxbaum noted that for her patient, to speak in her native tongue facilitated recollection of traumatic events associated with leaving her country of origin. Thus, she suggested that childhood recollections might only be emotionally accessible in the language in which such memories were encoded (Buxbaum, 1949, in Clauss, 1998), whereas the use of the second language worked to create emotional distance. Greenson's (1950) work also supports the idea that switching to a second language in therapy may constitute a defensive maneuver to avoid emotionally laden material. Her contribution takes a step further by introducing the idea that bilingual patients experience different representations of the self according to the language being spoken. In her work with a bilingual patient, for instance, the patient described that in German she was a dirty child, whereas in English she perceived herself as an anxious woman (Greenson, 1950, in Clauss, 1998).

More recent contributions have also supported the idea that for bilingual patients their mother tongue is their "feeling language," namely their personal way of understanding and communicating about affect and the vehicle that allows them to access an earlier place and time (Gowrisunkur, Burman, \& Walker, 2002). In line with the seminal work of Buxbaum and Greenson, Perez-Foster (1992 \& 1996) proposes that bilingual patients use language as a "character organizer": "Linguistically organized self-states originate in language-specific selfother configurations. They represent schematic domains of self-experience composed of affective, imagistic, cognitive, and behavioral elements" (p.117). She adds that the power of language to evoke early relational environments lies in the evocation of original feeling states (1992). In her case illustration, a young Chilean dancer experiences a powerful explosion of early developmental material when she switches to Spanish, her mother tongue. Perez-Foster argues then that treatment in the mother tongue can thus offer enhanced transformational possibilities for self and object.

In addition to these clinical observations on the impact that switching from one language to the other appears to have on psychotherapeutic processes, other qualitative studies have examined therapists' perspectives on the same issue. Findings from these studies suggest that when translating experiences, particularly affectively charged experiences, from the primary language in which they occurred, often forces bilingual clients to modify and/or simplify the complexity of such experiences, which ultimately results in a loss of detail and vibrancy (Kokaliari et al., 2013; Kokaliari, 2011; Schrauf, 2000). Moreover, language in psychotherapy plays an important role when processing trauma. Therapists emphasize that trauma-related material may be difficult to express in a second language, while the use of the mother tongue appears to facilitate access and expression of such material, as well as helping clients process traumatic experience more easily (Bowker \& Richards, 2004; Kokaliari et al., 2013; Kokaliari, 2011; Schrauf, 2000). In contrast, trauma survivors tend to use their second language as a defense when they need to view and compartmentalize unintegrated experiences by expressing them in extremes, an idea that has been widely supported in the literature (Kokaliari et al., 2013). 
Additionally, other studies have found that Spanish-English bilingual therapists generally use language switching to build a working alliance and bond with their bilingual Latino/a clients (Santiago-Rivera, Altarriba, Poll, Gonzalez-Miller, \& Cragun, 2009, in Perez Rojas, Gelso, \& Bhatia, 2014).

The idea that the primary and secondary languages afford different levels of emotionality and allow access to different kinds of memories is also supported by linguistic and neurophysiological studies (Byford, 2015). Findings from various experimental studies suggest that, firstly, linguistic memories are more likely to be elicited by the language in which the event took place, and secondly, such memories are more detailed and emotionally intense in the language in which they were linguistically encoded (Byford, 2015; Harris, 2010; Marian \& Kaushanskaya, 2004; Marian \& Neisser, 2000). Neurophysiological studies, on the other hand, indicate that large segments of the bilingual's languages are stored in separate areas of the cortex. Many of these studies suggest that second language is channeled through explicit memory and thus lacks the non-verbal sensory representations associated with the primary language, leading to a difference between sensorily "embodied" versus "disembodied" language (Paradis, 1994; Pavlenko, 2006). Thus, the same word in two languages, carrying the same conceptual meaning, is linked to two separate streams of associations, idiosyncratic meanings, and specialized affective accompaniments (Perez-Foster, 1996). Consequently, the verbalization of emotionally charged material in the second language may cause certain experiences to remain vague and unreal (Pavlenko, 2006).

\section{Ethnic/Cultural Matching and the Psychotherapeutic Process}

Similarly, the role of bilingualism in psychotherapy, ethnic matching, and its potential implications for psychotherapy has also been discussed in the literature. As context, it should be noted that the concept of "ethnic matching" is quite imprecise and complex, and that there is greater variability within ethnic groups than researchers and clinicians typically anticipate (Cabral \& Smith, 2011). With this in mind, the general presumption has been that matching patients and clinicians of the same ethnicity may carry benefits for the treatment at various levels, including therapeutic alliance, adherence, and treatment outcome (Cabral \& Smith, 2011; Constantine, 2002; Kohatsu, Dulay, Lam, Concepcion, Perez, Lopez, \& Euler, 2000; Sue, 1998). Nevertheless, research findings on the benefits of ethnic matching for psychotherapy have been inconclusive (Chao, Steffen, \& Heiby, 2012; Karlsson, 2005).

In the most recent meta-analysis that summarizes the literature on ethnic matching, the data indicate that although patients tend to prefer having a therapist of their own race/ethnicity and tend to perceive therapists of their own race/ethnicity more positively than others, ethnic matching does not appear to have a significant effect on patients' improvement in treatment (Cabral \& Smith, 2011). Nevertheless, there is a high degree of variability in the research data that suggests that such findings differ between groups. Particularly, ethnic matching appears to be more salient for people of color than for White/European Americans, with African Americans and Hispanics expressing strongest preference for therapists of the same background (Cabral \& Smith, 2011). Moreover, for patients who identify more strongly with their ethnic minority group, such preference for ethnic matching appears to be stronger (Swift, Callahan, Tompkins, 
Connor, \& Dunn, 2015). An important finding in a recent study conducted by Chao and colleagues (2012) indicates that ethnic matching may actually improve working alliance and address potential barriers to treatment engagement. This is significant, considering that results from the same study indicate that a good working alliance augments recovery status (Chao et al., 2012).

In addition to this body of literature from meta-analyses and experimental studies, case studies contribute to a more nuanced understanding of some of the clinical implications of ethnic matching for psychotherapy, capturing the complexity of ethnic and other aspects of one's cultural identity beyond homogenized stereotypes. Overall, this body of literature argues that patients' assumptions of the therapists' familiarity with, and acceptance of, their notions of self, the world, values and feelings - all of which are grounded in the therapists' being of a similar ethnic background and speaking the same language - pave the way for differences and conflict to be tolerated, and for intimacy and attunement to emerge (Gowrisunkur et al., 2002; Smith \& Tang, 2006).

For instance, Gowrisunkur and colleagues (2002) describe a case in which both clinician and patient were of South Asian origin and could access a common language, and yet differed in religion, social class, status, and gender. The authors suggest that the "cultural matching," facilitated by the shared experience of language and ethnicity, created a secure base from which the patient was able to explore his vulnerabilities and face his worst fears (Gowrisunkur et al., 2002). In a separate case, Smith and Tang (2006) highlight the process in which a patient, who felt alienated and marginalized in the larger society, focused on the shared "Asianness" with the therapist while denying the reality of being from dissimilar cultures in order to allow for the development of a therapeutic space. The case illustrates how patients may cling tenaciously to the similarities in the initial phases of therapy, while they are more able to tolerate differences as the treatment progresses.

In summary, the literature on psychotherapy processes related to the treatment between like-matched bilingual patients and therapists who share a similar ethnic background identifies potential treatment-enhancing effects of actively incorporating these dimensions of cultural identity into the therapeutic work. First, research on bilingualism points to clear differences in the degree of emotionality attached to each language, with potential augmenting effects of inviting patients to switch languages in therapy in order to help them experience emotions more vividly and process them to completion. Moreover, in patients with trauma histories, the ability to switch to their mother tongue in therapy may increase their capacity to recall with greater detail traumatic experiences, in a way that may not be possible when using a second language. Second, in a related vein, the literature on ethnic matching indicates that having a therapist of the same or similar ethnic background - although more relevant to preference for and perceptions of therapists than to the actual effectiveness of the therapy-does seem to enhance the therapeutic alliance and facilitate a secure space from which patients are more likely to experience vulnerability and be less guarded. 
Competence Strategies in the Treatment of Relational Trauma: The Case of "Rosa"

N.Vigoda Gonzales

Pragmatic Case Studies in Psychotherapy, http://pcsp.libraries.rutgers.edu

Volume 14, Module 1, Article 1, pp. 1-57, 09-12-18 [copyright by author]

\section{Rationale for Incorporating a Language and Ethnic Identity into AEDP}

As described above, Accelerated Experiential Dynamic Psychotherapy (Fosha, 2000) is a particularly well-suited model for the treatment of relational trauma sequelae, as it aims to heal the wounds that such trauma wreaks by co-creating new emotional and relational experiences within the therapeutic dyad, and thus potentiates deep and lasting psychological change (Fosha, 2000, 2004; Gleiser et al., 2008; Lipton \& Fosha, 2011). Consequently, it is in the creation of relational safety, and in the organic experience of the original relational trauma and subsequent emotional processing, that the transformative potential of AEDP lies.

Taking this into account, issues related to language and ethnic/cultural identity may pose important challenges to the implementation of AEDP with the bilingual and bicultural patient. Firstly, as the literature suggests, the use of a second language in therapy may function as an impediment to emotional expression and affective involvement, and may produce affective detachment. In addition to this, recollection of traumatic experiences may remain vague and unreal. Consequently, the exclusive use of a second language could potentially interfere with a patient's ability to experience core affect, the first state transformation in AEDP, by getting in the way of somatically experiencing emotions connected to the original relational trauma. Secondly, the patient's assumptions about how similar or different they are in regards to their therapist, based on the patient's ethnic and cultural identity, may impact the establishment of a safe therapeutic space and the client's initial willingness to trust the therapist. Thus, although not a required variable for the creation of a strong therapeutic alliance, ethnic matching may accelerate the co-creation of relational safety in AEDP.

With this in mind, it appears that actively incorporating bilingualism and ethnic matching into the implementation of AEDP with bilingual and bicultural patients could have augmenting treatment effects, and may also address potential barriers to treatment engagement. As Clauss (1998) accurately puts it, "the relationship between language and culture is inextricable and jointly bound to the psychotherapeutic process" (Clauss, 1998, p.188). In the case of AEDP with the bilingual and bicultural patient, inviting patients to switch languages in therapy and use their mother tongue, as well as judicious disclosure of the therapist's ethnicity and shared bilingualism, may foster the alliance and deepen the therapeutic process.

\section{ASSESSMENT OF THE CLIENT'S PRESENTING PROBLEMS, GOALS, STRENGTHS, AND HISTORY}

\section{Presenting Problems}

As mentioned above, when treatment started, Rosa was a bilingual, 63-year-old divorced Hispanic woman living alone, who retired four four years ago after working as a school counselor for more than two decades. She had been married for eight years to an Irish-American man, who was the father of her son, and saw the marriage as a "way-out" from her family.

Rosa came to the clinic presenting with feelings of desperation due to her 36-year-old son's worsening alcohol abuse problem, and her difficulty confronting him for fear that she 
would "drive him away." His behavior was triggering disturbing memories, thoughts, and feelings about her own childhood experiences with her alcoholic father. She felt anger and shame toward her son, and was reacting with intense guilt about this emotional experience. Rosa also reported difficulty sleeping, disturbing nightmares in which she lost her son, and episodes of "panic" characterized by heightened anxiety, rapid breathing, heart palpitations, nausea, and inability to think clearly. Rosa was quite isolated, reporting having contact only with her son, his wife, and her oldest sister, and avoided meeting new people because she feared being rejected.

Additionally, Rosa experienced intense feelings of sadness and guilt when recalling events about her childhood and her relationship with her siblings. With her mother's passing a year and a half prior to the evaluation, existing conflict with her siblings had exacerbated, and she became increasingly withdrawn and alone in her own grief. Painful experiences about her childhood were "coming back" to her, and she wished these memories would "go away." Without work and caregiving responsibilities to occupy her mind, Rosa described her symptoms as unbearable. She felt hopeless and thought she would be better off dead, but adamantly denied she would act on those thoughts.

\section{History of Psychological Treatment}

Rosa reported several episodes of depression in the past. She stated that during a good portion of her 8-year-long marriage, she felt depressed, and described feelings of sadness, guilt, hopelessness, anhedonia, irritability, sleep and appetite disturbances, passive suicidal ideation, and lack of interest in sex. In her thirties, Rosa received psychotherapy for 2 years to address difficulties associated with the dissolution of her marriage, as well as balancing work, school, and being a single parent. On a second occasion, at the age of 40, Rosa received therapy for "emotional difficulties" (i.e., anxiety and depressive symptoms) related to heightened legal conflict with her ex-husband and to her son's behavioral problems. She described both therapy experiences as helpful and successful, and was able to resolve the issues that motivated her to seek help. Nonetheless, she had never addressed her history of relational trauma.

\section{Relevant Personal History}

Rosa was the middle of nine siblings. She was born in a Spanish Caribbean island and immigrated with her family to the United States at the age of three. Rosa reported a long history of trauma starting in childhood, marked by her father's alcoholism and the witnessing of domestic violence. At the same time, she recalled being the target of emotional abuse, bullying, the ridicule of her siblings, a feeling of being different, and rejection by her siblings. Rosa stated that her mother did not protect her from this abuse, and, on the contrary, rarely provided her with affection, attention, and nurturance. She was frequently criticized and humiliated by her mother due to her darker skin tone and coarser hair. Rosa described her attempts to gain her mother's attention and affection by doing chores and being overly obedient, and acknowledged doing so until her mother's death. Despite this, she always felt "invisible".

While growing up, Rosa recalled spending a lot of time on her own. She described herself as an "introvert" who had no friends because her parents "banned" her from socializing with other children. In school, she described herself as an overachiever and skipped $7^{\text {th }}$ grade. After 
finishing high school, Rosa attended college, and subsequently attempted to pursue a graduate degree in counseling. Nonetheless, after one year she dropped out because she felt she did not fit in: "I tried to get out into the world, but it didn't work for me, so I went back into myself." She returned to school a few years later and finished her degree.

After Rosa's husband had left her and her son and asked for a divorce, Rosa devoted herself to the care of her son and her work as a high-school guidance counselor up until her retirement four years ago. During that time, Rosa reported having "few friends," but struggled to maintain those relationships upon retirement, claiming that she felt they did not put enough effort into continuing the friendship. She spent the first part of her retirement caring for her mother, but since her mother's death, Rosa felt increasingly isolated and lonely.

\section{Initial Presentation and Response to Interventions}

During the first few evaluation sessions, Rosa was agreeable and engaged, but also appeared anxious, exhibiting hand tremors and overall discomfort. Her anxiety appeared to dissipate as the sessions progressed. Soft-spoken and articulate, Rosa became tearful whenever she even tangentially touched upon events from her childhood and her relationship with her family. When I asked her to elaborate, she would say, "I can't look at this right now, it is too much to deal with... I need to focus on my son." I hypothesized that focusing on her son's drinking functioned as defensive avoidance of the overwhelming feelings triggered by those traumatic experiences. At times, Rosa was circumstantial, adding many details to her story, and barely leaving any space for me to interject. She felt hopeless and alone, and thought she would be better off dead, but denied that she would ever act on these thoughts.

Throughout the evaluation phase, as part of the Short Term Dynamic Therapy course, different therapy models were tested for their appropriateness. To challenge some of Rosa's defenses and assess her responsiveness to transference interpretations, I used confrontational interventions from Davanloo's (1980) Intensive Short-Term Dynamic Psychotherapy (ISTDP). In response to this approach, Rosa appeared to become affectively flooded and more guarded. In contrast, Rosa was significantly more receptive to attachment-based, relational, and experiential interventions from Fosha's (2000) AEDP and from Levenson's (2010) Time Limited Dynamic Therapy. In particular, AEDP's affirmative stance, and a focus on amplifying emotions, appeared to help Rosa deepen affective exploration in the here-and-now and strengthen the therapeutic alliance.

Similarly, on a few occasions when referring to her history of relational trauma, Rosa used words in Spanish. Unaware of my ethnic background and my knowledge of the language, Rosa would try to translate those words into English, and in that process, distanced herself from the emotion originally evoked. The judicious self-disclosure of my own bilingualism was deemed clinically appropriate. Rosa reacted with surprise and excitement when learning that I spoke Spanish, and that this too was my mother tongue. This process will be described in more detail in the section 6 below, Course of Treatment. 


\section{Quantitative Assessment}

Three quantitative measures were used to assess Rosa's symptoms at the start and end of treatment. I completed the first one, the Hamilton Depression Rating Scale (HDRS), at the end of therapy based on two perspectives: Rosa's initial presentation and her presentation at termination. In addition, during the final, follow-up session (session number 24), Rosa completed two psychometric measures--the Trauma Symptom Inventory-2 and the Outcome Questionnaire45-as indicators of her present experience. She was also asked to complete these same two measures based on her recollection of her symptoms at the beginning of treatment. Although not the standard way of administering questionnaires in order to validly assess Rosa's state pre- and post- treatment, this is an assessment approach that measures Rosa's subjective evaluation of her growth throughout the psychotherapeutic process.

The first measure, the Hamilton Depression Rating Scale (HDRS; Hamilton, 1980), is a semi-structured interview that consists of 21 items (scoring based on the first 17 items) assessing the whole spectrum of depressive symptoms, including affective, cognitive, and somatic symptoms. As Table 2 indicates, Rosa's HAM-D score at the beginning of treatment was 30, indicative of very severe depression. This is consistent with her initial presentation and the diagnosis of Major Depressive Disorder, recurrent that she received at intake.

The second measure, the Trauma Symptom Inventory-2 (TSI-2; Briere, 2011), consists of 136 items that assess complex symptomatology associated with exposure to trauma. It contains two validity scales, 12 clinical scales, 12 subscales, and four factors (see Table 3 for scales, subscales, and factors). Rosa's pre and post scores on the TSI-2 are presented in Table 4. Based on a $T$ score distribution, there are three score ranges: normal $(T<60)$, problematic $(T=$ 60-64), and clinically elevated $(T>64)$.

As the table illustrates, Rosa's validity scales at both times were in the normal range. Based on her recalled state at the onset of treatment, Rosa's TSI-2 profile is noteworthy for clinically elevated scores on the following scales, subscales, and factors: Anxious Arousal (including the Anxiety subscale), Depression, Intrusive Experience, Defensive Avoidance, Suicidality (including the Ideation subscale), Insecure Attachment (including both subscales), Somatic Pain, Self-Disturbance, and Post-traumatic Stress. Additionally, Rosa scored in the problematic range on the Somatic Preoccupations scale, the Hyperarousal subscale, and the Externalization and Somatization factors. This profile is consistent with Rosa's clinical presentations at intake and her endorsement of symptoms of Complex PTSD.

The third measure administered, the Outcome Questionnaire-45 (OQ-45; Lambert et al., 1996), is a 45-item self-report instrument that is designed to evaluate patient progress throughout the course of treatment and at termination. It generates a total score and three subscale scores: (1) Symptom Distress, (2) Interpersonal Relations, and (3) Social Role. Rosa's pre- and posttreatment scores are presented in Table 5. Three of her scores at the onset of treatment - Total score, Symptom Distress, and Interpersonal Relations - were above the clinical cut-off. Again, this is congruent with the high degree of symptomatology, interpersonal problems, and decreased satisfaction with life that Rosa presented with at intake. 


\section{Diagnosis}

As shown in Table 6, at the onset of treatment, Rosa met DSM-IV-TR criteria for Major Depressive Disorder, recurrent, severe. She endorsed low mood, anhedonia, sleep and appetite disturbances, low energy, intense feelings of guilt and hopelessness, and passive suicidal thoughts. Additionally, Rosa exhibited several symptoms typical of anxiety disorders, particularly PTSD, but did not meet full criteria for any one of these disorders in particular. She endorsed overwhelming anxiety, disturbed sleep/nightmares, disturbing thoughts and memories of her past, avoidance of people/places/topics related to traumatic memories, overwhelming worry, and fear of being judged by others. These symptoms were negatively impacting her relationships and capacity to enjoy life. Nonetheless, a diagnosis of Anxiety Disorder NOS was not provided, given the DSM-IV-TR's guidelines (i.e., the diagnosis should not be given if criteria are met for a specific Mood Disorder).

\section{Strengths}

Rosa had plenty of strengths. Not only was she bright, she was also quite capable of adopting an observing and self-reflective stance. In particular, she recognized dynamics in her family that contributed to many of her struggles, and acknowledged that by overly focusing on her son's issues, she was avoiding more painful aspects of herself and her past. Rosa was also able to tolerate my attempts to gently challenge her avoidance of issues rooted in the past, without becoming overwhelmed by anxiety. Although her choice of remaining disconnected from members of her family initially appeared to contribute to her difficulty resolving ambivalence toward them, it later proved to serve a protective function by removing her from a noxious environment.

Rosa demonstrated that she was capable of seeking help and emotional support when needed, as evidenced by her two previous courses of therapy as well as this one. Her history of high academic achievement, work stability, and ability to be a supportive and responsible single mother despite her history of relational trauma, were testament to her outstanding resilience and resourcefulness. Finally, she was motivated for therapy, and recognized the importance of gaining awareness into her intrapsychic and interpersonal conflicts in order to stop being paralyzed by them, and deeply wished to engage in more adaptive and fulfilling relationships. Her intelligence and high level of insight proved to be assets throughout the therapy process.

\section{CASE FORMULATION AND TREATMENT PLAN}

\section{Formulation}

Rosa's history of childhood relational trauma and the emotionally impoverished environment that she was exposed to wreaked deep wounds to her sense of self, her sense of others, and her ability to experience emotions. Not only was Rosa terrified of her alcoholic father, but also of her harsh and critical mother who failed to provide her with a sense of safety. Moreover, she was left unprotected from the ridicule, rejection, and disdain of her siblings. She was also painfully aware that her sister was her parents' "favorite" (e.g., she described her sister 
as having straight hair and white skin, and recalled that her father used to braid her sister's hair), whereas Rosa's endless attempts to get her mother's approval and love would be met with scorn and reprimands.

Rosa's past clearly revealed a chronic exposure to unbearable affective experiences (Fosha, 2000) of feeling helpless, worthless, and broken, and she had to deal with these on her own. This interfered with her capacity to experience and process intense emotions. Instead, she tried to avoid and/or overregulate them, ultimately sacrificing part of her emotional world in order to preserve the attachment to her parents and siblings, and protect herself from such terrifying experiences. Her sense of self was also deeply wounded and negative, subject to strong feelings of inadequacy and guilt (e.g., when she skipped third grade she felt guilty for her sister). Thus, Rosa frequently asked herself, "What's wrong with me?" and felt easily rejected and/or taken advantage of by others. Her position in her family - as the outcast and a target of ridicule and rejection by most of her siblings - deeply impacted her ability to form interpersonal relationships and to assert herself. She was in conflict: she longed for closeness and nurturance, and yet was terrified of being bullied, rejected, and abandoned.

Immersed in such a toxic environment, Rosa developed defenses that in her childhood may have been protective. For instance, withdrawing and avoiding standing out were adaptive strategies while growing up. Keeping feelings and her needs for closeness and attention to herself may have prevented her from being called "stupid" or "useless" by her mother. However, Rosa continued to use these strategies in adulthood. To defend herself against the anxiety generated by the tension between her yearning for closeness and her fear of rejection, Rosa acted passively and pleasingly to avoid confrontations (especially with her son); subjugated her needs (with her sister); and ultimately withdrew when these fears became more threatening. She also had difficulty experiencing and modulating anger, particularly toward those closest to her like her mother and her son. She turned those feelings inward and either felt incredibly guilty, or assumed a caregiving role, as she did with her mother. It is as if she felt these were the only paths to preserve the attachment to those she loved and depended on.

Inevitably, Rosa's long-term reliance on these defensive strategies contributed to her distress and to her sense of being paralyzed in a state of overwhelming despair. Her submissiveness and passivity in relationships not only left her plagued by powerful unmet needs for security and comfort, but also increased the chances that others, such as her siblings, could continue to take advantage of and victimize her. Rosa's hypersensitivity to rejection predisposed her to interpret benign day-to-day interactions as signs that she did not fit in, and subsequently she felt to unwanted. By withdrawing from others, she avoided confronting these feelings of rejection, humiliation, and guilt, but also remained isolated in terrifying worlds of unbearable, and often dysregulated, emotions. As Fosha (2000) eloquently puts it,

Chronic reliance on defenses constricts both relational and affective experience, for what gets defensively excluded and buried are not only emotions such as grief and rage that are too painful and intense, but also adaptive functions intrinsic to these emotions, such as a sense of perspective, self-worth, and strength (Chapter 4, section 4, paragraph 3). 
This maladaptive cycle, although always present, was more intensely activated when circumstances triggered strong emotions, or when a relationship with a loved one was under threat. It is likely that Rosa's investment in work and the care of her son after the divorce, and later her involvement in her mother's care, helped maintain a tolerable equilibrium. Nonetheless, after her mother passed away, and with the subsequent exacerbation of conflict with her siblings, Rosa was stuck once again in a state of unbearable aloneness (Fosha, 2000) and was unable to process intense feelings of grief, sadness, and pain. The threat of losing the connection to her son -the only meaningful relationship Rosa had at the time-in the context of his worsening alcohol use was excruciating, and all too familiar within her longstanding history of relational trauma. Her customary ways of avoiding pain were no longer sufficient, and she found herself in a deep state of despair.

\section{Treatment Plan and List of Treatment Goals}

Rosa was familiar with therapy, having successfully completed two prior courses of individual treatment in the past. Nevertheless, she had used therapy to resolve transitory crises, and had purposely avoided addressing her complex history and sequelae of trauma and neglect. This time, it was evident that Rosa was ambivalent about exploring these traumatic experiences related to her family of origin, and yet she spontaneously acknowledged the enormous impact they were having in her day-to-day life. Consequently, prior to delving into such traumatic experiences, the initial stages of treatment needed to focus on the establishment of a strong therapeutic alliance and the development of relational safety (Fosha, 2000, 2003, 2006). This would pave the way to a greater tolerance of affect, an in-depth exploration of her history of relational trauma, and, in turn, the processing of core emotions connected to such history.

As a survivor of relational trauma who exhibited many symptoms of Complex PTSD and depression, Rosa appeared to be an appropriate candidate for short-term dynamic approaches based on attachment, experiential, and relational principles, particularly AEDP. Noteworthy was Rosa's history of being able to function well at her job and as a single parent despite the tremendous adversity and trauma she had been subjected to, as well as her capacity for reflection. These are characteristics of clients with whom AEDP appears to be highly effective (Fosha, 2006). Additionally, Rosa had responded favorably to AEDP-like interventions tested during the initial sessions of treatment, in comparison to other strategies from more confrontational models such as Davanloo's (1980) ISTDP.

In a similar vein, I hypothesized that actively incorporating into the treatment elements of Rosa's cultural identity — bilingualism and ethnicity — would strengthen our alliance, increase her feelings of safety, and help her connect emotionally to her history of relational trauma.

Consistent with the research literature (Perez-Foster, 1992, 1996; Clauss et al., 1998; Kokaliari et al., 2013), during the evaluation, when Rosa translated affectively-charged experiences from the primary language in which they occurred, from Spanish into English, her narrative seemed to lose emotional vibrancy, and she appeared detached from those experiences. I hypothesized that both a judicious self-disclosure of my own bilingualism (which implicitly revealed my own ethnic identity) and an invitation to switch languages in therapy would not only help Rosa experience emotions more vividly and process them to completion, but would also increase her 
sense of connectedness and attunement to me, her therapist. Ultimately, this would enhance her capacity to tolerate strong affect and face her heartbreaking history of familial abuse and neglect.

In sum, I recognized the importance of developing a fluid treatment plan aimed at repairing the damage caused by a wrenching history of relational trauma, including attachment disturbances, a negative sense of self, and avoidance of affect. Rosa's identity as a bilingual, bicultural woman was an important element to integrate into the treatment as it clearly impacted her ability to engage emotionally and to feel connected.

There were two overarching goals in Rosa's treatment plan: (1) to provide her with new experiences within herself and relationally with others, and (2) to provide her with new understandings regarding both emotional shifts within and relational shifts with others. This is in line with AEDP's assumption that it is through cycles of new relational and emotional experiences, and the exploration or meta-processing of these, that the patient can integrate such experiences into their core being. Consequently, the treatment goals presented below are neither in order of importance nor in linear progression.

Goal 1: Increase Rosa's sense of relational safety and trust in the therapeutic relationship.

This goal involved providing Rosa with new relational experiences by being explicitly empathic, affirming, affect-regulating, and emotionally engaged; in other words, by modeling what Fosha (2000) refers to as affective competence. This would help her see herself as worthy of love, affection, and attention. Interpersonally, the aim would be to get her to take more risks in expressing her needs for closeness and nurturance more directly without the fear of ridicule and rejection, and asserting herself without being punished. A second part of this goal would involve exploring these receptive affective experiences (Gleiser et al., 2008) of feeling seen, understood, and cared about, with the aim of helping Rosa develop a new understanding of such experience and integrate it into her sense of self and relationships. Additionally, disclosing my own bilingualism and inviting her to switch to Spanish during sessions would strengthen Rosa's sense of safety and connection in our relationship.

\section{Goal 2: Develop Rosa's insight into her defenses against closeness.}

This goal involved guiding Rosa through the exploration of ways in which she would resist a deep relational connection with me, despite intense longings for closeness. The aim would be to help her develop insight into her defensive operations against closeness (e.g., being overly passive, subjugating her needs, withdrawing), and to understand how continuous reliance on these left her feeling unneeded, unwanted, and unnoticed, and possibly invited others to be rejecting and dismissive.

Goal 3: Increase Rosa's ability to tolerate intense affect.

This goal is in line with AEDP's aim of providing new emotional experiences (Gleiser et al., 2008). Once a strong therapeutic alliance built on relational safety and trust was developed, and some of Rosa's defenses against closeness had been bypassed, the aim would be to help 
Rosa fully experience intense core affect associated with her history of relational trauma. I used experiential techniques to track Rosa's feelings in the moment, by employing experiential techniques and by integrating her bilingualism. In these ways I intended to help Rosa to become aware of and to experience deep feelings of pain, grief, and anger, which were were likely evoked in the company of a trusting other, ultimately leading to an increase in her capacity to tolerate distress.

Goal 4: Help Rosa relinquish her defenses against the experience of affect.

I hypothesized that in the emergence of intense feelings, Rosa would either attempt to overregulate and/or avoid such experiences by using tactical defenses such as changing topics or talking incessantly, or become dysregulated in a state of what Fosha (2000) refers to as feeling but not dealing. In such a state, inhibiting emotions such as anxiety or shame would be likely to emerge. By slowing Rosa down and exploring her reactions to being exposed to intense affect, my goal was to assist her in developing awareness and a new understanding of the defenses that were mobilized and gently challenge them.

Goal 5: Process adaptive emotions to completion.

Once Rosa moved from defensive avoidance to awareness of her emotions, the goal would be to guide Rosa through the processing of such affective experience directly connected to the original relational trauma of the emotional neglect and abuse she was, and continued to be, exposed to. This would involve helping her feel, and reflect upon, such emotions without becoming overwhelmed, and in turn experience a sense of relief and self-compassion.

Goal 6: Improve Rosa's sense of self.

This goal involved helping Rosa gain insight into, and understanding of her so far internalized negative sense of self that was a product of her history of trauma, and in turn assist her in accessing and maintaining a more positive and realistic sense of self, free of shame, guilt, and feelings of worthlessness.

Goal 7: Reduce Rosa's hypersensitivity to rejection and avoidance of social interactions.

I planned My plan was to help Rosa integrate all those new relational and emotional experiences described above, and help her become aware of her interpretation of benign day-today interactions as rejecting in an effort to improve her capacity and willingness to connect with others and reduce her sense of isolation.

Goal 8: Alleviate Rosa's depressive and PTSD-like symptoms. 


\section{COURSE OF TREATMENT}

\section{Initial Phase: Sessions 1 -9}

Sessions $1-2$ : Evaluation and Introduction to Therapy

Consistent with AEDP and my own therapeutic preferences, and starting from my first encounter with Rosa, I focused on building a strong alliance with her. An important goal during the first two evaluation sessions was to assess Rosa's clinical presentation and design a formulation that would serve as a map to guide the treatment and interventions. As was mentioned above, this case was assigned to me as part of a course in short-term dynamic therapy. Thus, in addition to gathering a detailed history and understanding of Rosa's symptomatology, current functioning, and interpersonal style, this formulation exercise for the course also involved trying out a few different short-term psychodynamic approaches to determine their appropriateness for Rosa's case.

During our first evaluation session, it was evident that Rosa had a lot to say and words seemed to gush out of her mouth. She made sure to attribute her distress to her son's drinking, and to emphasize on multiple occasions her wish to make this her goal for therapy. When I queried about her reason for seeking treatment at that particular moment, Rosa stated: "I'm the mother of someone who drinks... I've been in denial about this and I don't know how to handle this situation... I don't know how to talk to him about this." As she was speaking, I was immediately impressed by Rosa's capacity for insight and self-reflection, as she quickly established connections between her son's behavior when intoxicated and her own alcoholic father; and as she spoke about this, I started noticing signs of trauma sequelae. Prior to our first meeting, the only information I had about Rosa was from a short telephone screening, where there was no mention of a history of trauma. Nonetheless, she described with a soft, barely audible tone of voice how seeing her now adult son drunk was as if she was "experiencing it all over again," that it was "too strong," and that she felt she "couldn't handle it." To me these were signs of re-experiencing symptoms and of emotion dysregulation.

As I continued gathering details about her history, I noticed that whenever issues related to her family of origin were even superficially touched (e.g., a strained relationship with her siblings and her father's aggressiveness while intoxicated), Rosa engaged in what Fosha (2000) refers to as "feeling but not dealing," that is, being overwhelmed with feeling and unable to cope. Rosa seemed terrified - she trembled - and she seemed to want to run out of the room. My invitations to further elaborate on these topics were met with resistance and the mobilization of defenses. "I want to set aside these feelings," she would say. As I pointed her efforts to stay away from those topics and their associated emotions, she capitalized on her desire to focus on her son. Delving into her family relationships was "too difficult" and would only "interfere" with her goal of understanding what she could do to help her son.

From the very beginning, I noticed Rosa's frequent mobilization of a variety of defense mechanisms whenever affect-laden material arose. She spoke incessantly and rarely gave me space to interject; she rapidly changed topics whenever we seemed to be getting closer to 
Competence Strategies in the Treatment of Relational Trauma: The Case of "Rosa"

N.Vigoda Gonzales

Pragmatic Case Studies in Psychotherapy, http://pcsp.libraries.rutgers.edu

Volume 14, Module 1, Article 1, pp. 1-57, 09-12-18 [copyright by author]

meaningful material; and she added an incredible amount of detail to some of her stories, which required me to constantly redirect her. On the other hand, she was articulate, exhibited an impressive capacity for insight, and seemed knowledgeable about therapy.

In considering which short-term dynamic models would be appropriate for her, I decided to try out techniques from Davanloo's (1980) Intensive Short Term Dynamic Psychotherapy (ISTDP) and assess Rosa's responsiveness to confrontation and interpretation of her defenses. According to this model, if a patient responds to such confrontations and interpretationsusually referred to as a trial interpretation-with increased affect followed by a production of memories and associations, his/her suitability for this particular model would be indicated (Messer \& Warren, 1995). I observed that my attempts to challenge some of Rosa's defenses as noted above - which Davanloo (1980) refers to as tactical defenses - by employing ISTDP interventions were met with strong resistance, and seemed to set us farther apart. For instance, after Rosa stated a few times that she was on the "verge of crying," I responded with a neutral tone of voice: "You say you're at the verge of crying and yet I don't see any tears." She responded by insisting she had cried "enough" about this (her turbulent relationship with her family), and quickly moved away from the subject, clearly indicating her resistance to elaborate on her defense against affect. Later in the session I added: "You seem to want to fill the space with words as if you were afraid of what may happen if you slow down." To this confrontation, she responded laughing defensively, "Well, I barely know you!" and her demeanor indicated she felt irritated and disconnected from me. I hypothesized that such a confrontational style typical from ISTDP might interfere with our ability to establish rapport, or slow down this process. Additionally, it appeared that Rosa was not yet ready to relinquish her defensive operations against intense feelings.

Later in supervision, my supervisor and I wondered about Rosa's defensive reaction to such a confrontational style. The more information I gathered about Rosa's past, accompanied by her non-verbal reactions to my attempts to find out more about her familial history, the more convinced we became that she was indeed a survivor of relational trauma. It was evident that Rosa struggled to trust others, that her attachment style was insecure, and that a sense of safety in the relationship with me, her therapist, needed to be established first and foremost. I hypothesized that short-term dynamic models based on relational and attachment principles would be most appropriate for fostering a sense of safety and trust that would enable Rosa to tolerate any affective exploration and review of her trauma history.

I decided to test this and modified my stance as a therapist, moving away from the more technical neutrality typical of structural/drive dynamic approaches, like Davanloo's (Messer \& Warren, 1995), to a rather explicitly affirming, validating, empathic, and emotionally engaged stance. In contrast to Rosa's reaction to a confrontational style, her response to such an affirming and validating therapist stance - typical of attachment-based and relational models like Fosha's (2000) Accelerated Experiential Dynamic Psychotherapy and Levenson's (2010) Time-Limited Dynamic Psychotherapy_-Rosa appeared more attuned to her feelings and able to tolerate them. While she was still strongly overwhelmed by these emotions, such a therapeutic style allowed her to preserve the bond and connection to me. Based on her responses, I understood that in 
order to help Rosa get in touch with her traumatic history and learn to cope with her emotions, this type of approach would be much more fruitful.

Another significant element in the treatment that became evident during the evaluation phase was the importance of Rosa's cultural identity and its relationship to her history of relational trauma. In the evaluation sessions, she frequently switched to Spanish, particularly when recalling events from her childhood and interactions with her family of origin. For instance, when describing an incident in which her inebriated father physically attacked her mother while Rosa and her siblings stood in a corner crying, Rosa switched to Spanish to capture her mother's reaction by quoting her: "Estupidos! Que hacen ahi parados en vez de hacer algo?!" ("You idiots! What are you doing there standing instead of doing something?!"). The vibrancy and emotionality with which she portrayed the scene was quickly lost as she translated into English the meaning of these words. I noticed a similar pattern to her switching languages; not only did she use Spanish words when talking about affectively charged material related to her family history, but she appeared to disengage emotionally while attempting to accurately capture in English the meaning of such expressions. I understood the fundamental role that Rosa's bilingualism played in her ability to fully access emotions related to her history of relational trauma, and began considering the therapeutic effect of disclosing my own bilingualism.

By the end of our evaluation sessions, Rosa had started to spontaneously open up about her lifelong history of being victimized by her siblings, and emotionally neglected and abused by her parents. She realized how her mother's passing had 'brought the past very close to the present", and she was now experiencing a wave of intense and overwhelming emotions previously dissociated. It all felt "too intense," "too much," and "too painful;" and while she acknowledged the impact of her past on her current distress, she continued to recoil in horror at the prospect of opening the door to her past.

\section{Sessions 3 - 9: Building Trust and Relational Safety}

Cognizant of Rosa's history of relational trauma and her ambivalence about exploring it, my main focus during the remaining sessions of the initial phase of treatment was on solidifying a sense of trust and relational safety (Fosha, 2000; 2002; 2006). From the very beginning, my stance as a therapist was empathic and emotionally engaged, particularly taking into consideration the emotionally impoverished environment to which Rosa had been exposed. After the evaluation, it was evident that her determination to focus on the concerns over her son's drinking functioned as a defense mechanism to avoid the overwhelming feelings associated with those traumatic experiences. As she walked into our third session, she started by saying she needed to "control herself" and "slow down." Rosa was able to put into words what this overwhelming wave of emotions felt like:

Having all those feelings come out last week was not helpful... I ended up too overwhelmed, and I can't help my son if I am feeling like that... The best thing is if I can just leave it in the past and close the door... I just wanna walk away from all that pain, and not look at it. 
In line with the goal of providing Rosa, in therapy, with the opportunity to assert herself without being punished, I proposed a therapeutic focus that would honor the concerns related to her son, while at the same time recognizing her life-long efforts to be nurtured and cared for by her family, which had been met with rejection, victimization, and neglect. I empathized with the horror she experienced in the face of intense affect, validated her wish to avoid this at all costs, and expressed admiration for her resilience and resourcefulness despite the pain she had endured. At the end of this third session, Rosa had moved slightly away from defensive avoidance to greater awareness:

You remind me that there is a ME involved in all of this... I realize that living just for my son is a mistake... and I think is a way of not dealing with my own issues, my own loneliness... so focusing in him, despite the intensity, keeps those feelings hidden.

We discussed the time frame of our work together (I would work with her for approximately six months, until the end of the semester), and agreed to go at her own pace, assuring her I would not push her if it did not feel safe. In the next few sessions, Rosa would move back and forth between this defensive avoidance and a greater awareness and openness to explore the trauma.

Consistent with the treatment goals of facilitating new experiences and understanding, during this phase of treatment I employed interventions from relational and attachment-based approaches, including AEDP (Fosha, 2000) and TLDP (Levenson, 2010). Specifically, I frequently employed tentative statements ("I may have this wrong but..."); empathic exploration; and the accessing of emotions by encouraging Rosa to experience and express affect in the sessions, to deepen this affect, and to connect it to attachment-related feelings.

For instance, during the fourth session, Rosa reported feeling distressed about "not having a say" in her son's life. As she was about to move on to superficial details without leaving space for emotional exploration (clearly a defense), I encouraged her to slow down and elaborate on what it was like for her to "not have a say." Rosa anxiously said she felt what she had to say was "unimportant," and was again ready to move away from her feelings. Gently, I slowed her down and asked her to reflect on whether this feeling manifested in other relationships, to which she responded by laughing sarcastically, while tearing up, and saying:

All my life I've felt this way... I have a poor relationship with my siblings and there is nothing I can do about it... It's water under the bridge... It doesn't help me to go there.

In line with AEDP, by continuing to do a focused and empathic inquiry, constantly tracking her affect, Rosa finally described a life-long history of being victimized by her family, and the ultimate and total rejection by most of her siblings who shunned her after her mother's death, stating that she had been "traumatized" by the experience. This, as she put it, was just a "snapshot" of their dynamic. Despite her mother's failure to protect her from the abuse, her presence had "put a brake" to it, a brake that vanished with her departure. I empathically reflected on her chronic experience of having been ostracized by her family, while at the same time recognized the courage she had in opening up this chapter of her life in therapy, despite the overwhelming emotions evoked by it. Rosa was beginning to allow herself to experience core 
affect (Fosha, 2000); "I just don't want to live with that pain all my life," she added as she cried in the presence of a trusted other.

In following sessions, Rosa continued to spontaneously draw connections between this more recent "traumatic" episode and other more remote ones from her childhood, acknowledging always feeling unwanted, as if her family wished she "didn't exist." In recalling a conversation with her mother during our fourth session, she once again switched to Spanish. I had discussed in supervision the potential benefits of disclosing to Rosa that I spoke Spanish. Thus, as she was about to translate what she just had said into English, I gently interrupted to let her know that I, too, spoke the language. "Oh! Que bueno!" ("Oh! How wonderful!"), she exclaimed in excitement, and continued: "This is very helpful because a lot of these things that happened in Spanish have a different feeling to them," and immediately started using more words in her mother tongue without investing any cognitive energy into translating them. Consistent with the literature on bilingualism and degrees of emotionality attached to the first language, a shift in her affect occurred, becoming fuller and more vibrant.

While completing a genogram, Rosa elaborated on her life-long efforts to please her mother by being obedient, passive, and doing chores for her to get her attention and love, and taking this role in most of her relationships with her siblings. I noticed more clearly how she described herself negatively and blamed herself for her isolation, stating that she was "too slow," "always in a daze," never knowing how to respond when her siblings berated her. Even her achievements (i.e., signing herself up for religious instruction to make her first communion, skipping $7^{\text {th }}$ grade because of her academic performance) were tainted with a sense of guilt that, in her eyes, somewhat justified the punishment and ill treatment she received. As I continued to provide a "holding environment" where she could begin to experience the deep pain associated with these experiences, Rosa expressed a desire to be able to "talk about these things without getting so overwhelmed." I provided psychoeducation about post-traumatic stress symptoms and the problematic nature of avoidance. She closed the session by eagerly saying: "I'm so very happy you speak Spanish," a sign that this self-disclosure had strengthened our working alliance and increased her positive feelings toward therapy.

The relevance of an assumed organic connection between us based on our shared bilingualism was highlighted in the beginning of our sixth session when Rosa stated that she was "very glad" I spoke Spanish. She asked me if I was from a "Spanish background," as if she wanted to assess the extent of our similarities. When I answered affirmatively, and queried how this information changed things for her, she responded:

There are things that I feel are always left out when I say them in English... It makes me more comfortable that you speak Spanish, and that it is your native language.

She immediately followed by describing how therapy appeared to be helping her organize her experience.

A pivotal point in this phase of the treatment occurred during this session (\#4), when Rosa expressed realizing that she had always played the role of a victim in her family, that she 
was tired of this, and that she wanted to change this. She described her experience as feeling "confused and bewildered," wanting to set boundaries but unable to do so in the moment. Once again, I empathically reflected on her life-long struggle by stating, "You have put so much effort into being noticed, accepted, and nurtured, and despite all of your efforts, you end up feeling berated, bullied, and targeted by others." I shared with her the image that came to my mind as she described these struggles: a scared and terrified child in a corner who feels so overwhelmed that she cannot react. She responded by expressing feeling validated:

I couldn't have said it better... It is good you tell me this, because otherwise I wouldn't know (tearful, with her voice breaking up)... I've never really defined what's going on.

She reiterated her wish to change this and to no longer be a victim ("I wanna move past that! They don't hold the key to who I am... I don't want to feel like they can push me around anymore").

More and more accounts of interactions with her siblings in which she felt berated, rejected, or uncared for, were empathically explored, accessing and deepening the emotions, and processing them. My stance as a therapist provided her with a new relational experience: the opportunity to experience me as deeply interested in what she had to say without her needing to please me. Rosa began to exhibit greater tolerance of affect, and while still expressing her wish to "get over the pain without having to experience it," her acknowledgment of the unfeasibility of this was a sign that she had started to recognize the adaptive potential of core affect (Fosha, 2000; Gleiser et al., 2008).

In the next few sessions, Rosa reported improvements in her mood, no longer feeling "desperate." She continued to feel anxious about her son's drinking problems and marital conflict. Her son keeping distance and avoiding her reminded Rosa of the terror she experienced when he was an adolescent involved in gang activity. Nonetheless, Rosa was able to understand that she was no longer living the same circumstances, and that her son was a "grown man" who was no longer involved in such risky activity. Despite reporting distress both in relation to her son and recent upsetting interactions with one of her sisters, her accounts of these events were more organized and less frantic, and a sense of clarity began to emerge. For instance, when reporting on a distressing incident with the only sister she was still in contact with, Rosa was able to identify the emotions she experienced in that moment (i.e., humiliated, small, "like a cockroach"), and delineate her ambivalence about maintaining a connection to her. Moreover, Rosa acknowledged feelings of anger and indignation, and her struggles experiencing and expressing such affect. These were markers of an emerging transformation of what initially was diffuse distress, fear, and anxiety into more fully articulated emotions and memories - changes that AEDP seeks to promote (Gleiser et al., 2008).

At the beginning of session 9, which marked the end of the initial phase of treatment, Rosa described therapy as a "good experience" and expressed wishing that it lasted longer. "I'm really looking forward to working some things through," she added, and described feeling "elated." This indicated what AEDP refers to as a shift in the valence of intense emotions from negative (e.g., "too overwhelming" and "too painful") to positive and useful (e.g., "this is here 
for a reason") (Gleiser et al., 2008). Furthermore, the clear presence of positive relational affect, as well as the flow of deep therapeutic work, were indicators of a healthy therapeutic relationship (Fosha, 2000), which signaled greater readiness to engage in even more affectively charged work. Rosa had started to describe how therapy was becoming a space in which she was finally having the "opportunity for feeling sad" for herself, for really embodying the emotions of wrenching pain that she had not felt in the actual moments when the traumatic events were happening.

Additionally, at the end of this phase Rosa spontaneously acknowledged that up until now over-focusing on her son's concerns had protected her from facing the challenge of living her own life. This was relieving but at the same time saddening. She used a metaphor to describe the first glimmers of a realization that maybe it was finally time to let go:

It's like a train with many parts attached... and you finally get to the point where you can let go, let go of that part, detach from it, and let it go on its own.

Empathic exploration of this revealed that as she acknowledged her son's maturity and independence in dealing with his problems, this left more room for dealing with her trauma and for sorting out what she wanted to make of her life at this point, both of which were very anxiety provoking. She had ferociously defended against these underestandings, and now she understood it was time to focus on herself. "It feels like I'm drowning," she said as for the first time she truly connected to the sadness and the pain she had defended so strongly against.

\section{Middle Phase: Sessions 10 - 18}

During the middle phase of treatment, my main focus was on helping Rosa experience and process the emotions that once had seemed too overwhelming to face, in the context of a safe relationship with me. She had developed greater insight into her defensive avoidance, had expressed positive feelings toward therapy, and demonstrated readiness to move into the more affectively charged territory of her familial trauma. As I witnessed the repairing effect that the new relational experiences provided in therapy were having on her capacity to tolerate more intense affect, I continued to incorporate interventions heavily focused on AEDP. I was also observant of Rosa's switching of language, making attempts to use this to deepen affect. Notably, there were significantly more switches in language during this phase as she revisited her familial history in greater detail. I aimed to maintain at all times a therapeutic stance that was affirming, empathic, and emotionally engaged. This was in line with the goals of helping her experience herself as worthy of love and attention, to increase her distress tolerance, and to reduce chronic feelings of pain.

As we moved into this middle phase, Rosa presented more organized and less agitated in and out of sessions, despite the ongoing stressors she was facing. While her image of herself continued to be plagued by feelings of inadequacy, guilt, and shame, more glimmers of a healthier sense of self began to appear. In line with AEDP, I understood these feelings (i.e., guilt, shame, worthlessness) as inhibiting affect that needed to be bypassed in order to access the core, adaptive emotions of pain, anger, grief, and compassion for herself. A clear illustration of this 
Competence Strategies in the Treatment of Relational Trauma: The Case of "Rosa"

N.Vigoda Gonzales

Pragmatic Case Studies in Psychotherapy, http://pcsp.libraries.rutgers.edu

Volume 14, Module 1, Article 1, pp. 1-57, 09-12-18 [copyright by author]

process occurred in session 10, as Rosa discussed with great agony how she blamed herself for her son's problems and recalled a recurrent dream in which she lost her son, and how this feeling manifested in her life:

Rosa: Yes... the dream is different but the feeling is the same (getting choked up)

Nicole: Is it like panic, terror... [amplifying the feeling]

Rosa: And the other part of that feeling is that I DID it... That $I$ couldn't keep him, that $I$ didn't protect him (choked up) [inhibiting feelings of guilt and inadequacy]

Nicole: That YOU did it... that you ultimately lost him because it was your fault...

Rosa: (Crying) It is very hard... very hard... and I was so badly prepared to take care of him on my own, all alone, all alone [glimmers of core affect]...

Nicole: Yes... all alone... [Amplifying these core affective experiences]

Rosa: and it was so unfair, so unfair [more glimmers of core affect], because I tried to get people to help me...

Nicole: Just me imagining you in that situation... It breaks my heart [emotional disclosure to bypass the defense and help her tolerate the core affect]...

Rosa: Yes, and the other thing [ready to move away from the core affect of pain]

Nicole: Let's stay here for a second... You said something powerful... You were all alone... It wasn't fair... You were never able to take a break and deal with what you were feeling [mirroring and amplifying her experience of pain and possibly indignation].

Rosa: No I wasn't able to take a break... (Crying) It wasn 't fair [core affect of pain]

At this stage Rosa would move away from the core affect of pain and back to the inhibiting emotions of guilt, stating that she still "blamed herself." As we explored the origin of such sense of inadequacy, Rosa elaborated on the fact that her siblings used to compare her with a psychiatrically ill relative, to say that she had "una araña peluda en su Corazón" (a hairy spider as a heart; an expression that means having a bad heart), to call her "nerviosa" (too anxious), "loca" (crazy), and to think of her as incompetent. Her use of Spanish in recalling such mistreatment appeared to bring her even closer to the pain and sadness of being emotionally abused. Using anticipatory mirroring (i.e., responding emotionally to the patient as if she were expressing her feelings, were she able to do so) (Fosha, 2000), and repeating her words in Spanish, I shared my anger about the way she was treated and abandoned when she most needed her family (when her husband left her and she was left alone to care for a two-year-old by herself).

Before she moved away from that experience, I encouraged the awareness and experiential elaboration of this experience by asking her what it was like for her to hear me say that. With a soft tone, she stated: "It is very strange... I never made my case... I always went to 
therapy hoping to fix something that I believed was wrong with me." Then I proceeded to disclose how amazed and impressed I was at everything she had done for herself given those terrible circumstances, and once again asked her how it was for her to hear me say that. With tears in her eyes, she responded:

It's very good! It reinforces that part of me that thinks that I am competent, despite of what they say, that I can do things, and that part is important! But I've never acknowledged it... and seeing your reaction to what I share is... I'll tell you! I feel elated about talking to you!"

While this positive image of herself was still quite fragile, Rosa was finally starting to question what she had always believed, that there was something fundamentally wrong with her that explained the abuse and neglect she was subjected to.

In the following sessions, as Rosa more readily engaged in the exploration and experiencing of core affect, I continued to slow her down (since talking uninterruptedly was clearly a defense she used to avoid affective experience), and continuously mirrored and amplified painful feelings. As expected given her extensive history of relational trauma, I continued to empathetically experience her struggles tolerating intense feelings, and I then used my affect to counteract her patterns of avoiding emotional experience. Even when she clearly seemed unable to engage in certain experiential exercises, I used anticipatory mirroring and explicit empathy to provide her with the opportunity to see in me the experiences that she was not able to connect to at the time in which they originally happened. For instance, in session 11, Rosa articulated how her growing realization of her son's competency and maturity to deal on his own with his circumstances intensified her feelings of loneliness and emptiness, and a sense that she was "sinking." As she described not recalling feelings like this before ("I've never felt like I was sinking that way"), we explored her life-long use of defenses (i.e., withdrawal and dissociation) against such experiences

in order to survive. Rosa described her "strategies" as an 8- year-old to please her mother and avoid her siblings' rejection and ridicule, such as always playing in her bunk bed by herself, and never eating at the dining table with her family. Noticing that in her narrative Rosa was stuck in attempting to understand "why these things happened," I used portrayal, an AEDP experiential-affective strategy (Fosha, 2000), to help her connect to the affect associated with that traumatic experience:

Nicole: If you saw that little girl up in her bunk bed, what would you say to her? What would you do?

Rosa: (voice trembling) I don't know... I can't stay there [wanting to avoid the affective experience]

Nicole: Can you look at her? What was she wearing?

Rosa: (In a very low tone of voice) I have to tell you... I'm not in touch with it... I had such a deprived childhood in so many ways.

Nicole: Is it hard to look at that little girl? 
Competence Strategies in the Treatment of Relational Trauma: The Case of "Rosa"

N.Vigoda Gonzales

Pragmatic Case Studies in Psychotherapy, http://pcsp.libraries.rutgers.edu

Volume 14, Module 1, Article 1, pp. 1-57, 09-12-18 [copyright by author]

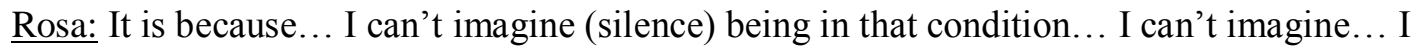
got so little attention, and even when I tried to get what I needed it was so hard...

Nicole: It is a horrible reality for someone to live... It breaks my heart to think of that little girl sitting in her bunk bed, all alone, afraid of being noticed... No wonder you were so withdrawn...

Rosa: I think it is only now that I am in touch with what I must have felt then

When Rosa returned for our next session she articulated that she had "reservations" about revisiting her childhood. She expressed a wish to sort things through, particularly the events that had followed her mother's death, and was motivated to reexamine her past; but as the memories and feelings were coming back she felt like "running away." As we reflected on her tendency to dissociate as a little child ("I was somewhere else... I was there but I wasn't there"), it was clear that she was now experiencing these "dreadful feelings" and the experience was "overwhelming." I understood this as a sign that I needed to slow down the pace of my interventions in order to make such experiences more tolerable.

The exploration of her tendency to withdraw and her feelings of loneliness revealed Rosa's conviction that she was doomed to be alone. "It's just that way," she said in response to my attempts to point out her efforts to rationalize her social isolation, and she followed by emphasizing that this was something she "wouldn't change. "I sensed that we were approaching an important, yet highly defended, territory, and decided to help Rosa process her struggle in talking about this. As I noticed her anxiety when she relayed her attempts to connect to other people ("I've sincerely tried to make progress, and I don't") - which usually resulted in a sense of futility and frustration - I asked her what came up for her when we discussed this subject. Her response was: "I don't know... I don't know how to talk about this... I don't want to try to figure it out anymore.' Rosa spontaneously drew connections between a past of being constantly humiliated by her family every time she looked for affirmation or admiration (e.g., her father ridiculed her when she showed him an outstanding report card), and her current inhibition in social circumstances.

The fragility of a positive sense of self that had begun to emerge became evident, as this exploration ultimately revealed again a more entrenched sense of inadequacy and social ineptness underneath Rosa's hesitation to connect to other people. Additionally, she reported instances in which she had been racially discriminated against, which had also contributed to her discomfort in social situations. It was clear that Rosa was not ready to change this and take more risks in expanding her social network. I hypothesized that a direct challenge by me of Rosa's use of this defense mechanism (i.e., withdrawal) would be unsuccessful. Instead, I resorted to providing validation and empathy about Rosa's investment in such a strategy (e.g., "No wonder that after being so humiliated you'd feel so afraid to open up to others," and "I'd too feel like it is safer to stay on my own"), as well as psychoeducation about racial micro-aggressions (Sue, 2010). At the same time, I emphasized the presence within her of a desire for a healthy connection. "I think it's better to wait and see... and take it slowly," she added as we ended the session. 
Rosa returned the following week reporting improvements in her mood and activity level. She described thinking about her pattern of social isolation, and reaching a realization that she had developed a "discourse" to inhibit herself, because "the task of getting through and getting comfortable was so complicated." In contrast to the previous session, Rosa appeared calmer and clearer in her exploration of her own ambivalence when connecting to others, and explained that she expected people would hurt her, reject her, or mistreat her in some way. She labeled this as "an inferiority complex."

At the same time, Rosa seemed determined to show me a healthier side of herself, and described her constant attempts to fight those feelings by doing things for herself, such as pursuing first communion at the age of nine, despite never getting praise or attention for such acts. I affirmed her resourcefulness and shared with her that I thought her behavior was so impressive and admirable, and invited her once more to reflect and elaborate on the experience of hearing me say this. With tears in her eyes, she acknowledged how difficult it was for her to take that in ("I want to run out of the room"), and stated, "It's like a huge indulgence to allow myself to accept that kind of reaction toward myself." This was a sign that Rosa continued to struggle to tolerate not only intense negative affect, but also intense positive feelings of pride and admiration, which explained her discomfort with my explicitly affirmative stance. I focused on acknowledging these two sides of herself: the one that was so wounded on the one hand, and the resilient, resourceful one who was, and had always been, curious about the world.

This oscillation between an entrenched negative and an emerging positive sense of self (or, in Fosha's words, a "true self") became more notable in the next few weeks of treatments. During session 14, Rosa reflected on an incident discussed in the past session, in which one of her sisters had treated her poorly in front of her ailing mother. Rosa justified her sister's behavior as jealousy and a desire for her mother's attention, and I reminded her of a similar incident in which she had also excused her sister's cruel behavior toward her. As we explored this pattern, Rosa offered insight into her use of rationalization in an effort to distance herself from the pain associated with being rejected and unwanted by her family. In line with AEDP, I understood Rosa's use of rationalization as inhibiting her capacity to experience core affective experiences of anger and pain associated with the abuse, and I aimed at helping her bypass, once again, these defenses. She continued using rationalization as she excused her mother's failure to protect her from her siblings' mistreatment and to provide her with nurturance and affection (e.g., the consequence of having nine children, as well as not receiving any attention in her own family), and stated she was incapable of feeling the core affect of anger toward her mother. As I continued to bypass her defenses and deepen her affect, Rosa disclosed with tears in her eyes that her mother used to tell her with disdain, "Pareces una gitana! Eres una sucia! Por que no puedes parecerte a tu Hermana o a tus primas?" ("You look like a gypsy, you're always dirty! Why can't you look more like your sister or your cousins [who had lighter skin]"). The following is an excerpt of an experiential exercise I used to help Rosa experience the core affect associated with this experience.

Nicole: If you give me permission, I'm going to ask you to do something with me. Imagine you go into a room and see a mother telling this to her daughter. What would you say, what would you do? 
Competence Strategies in the Treatment of Relational Trauma: The Case of "Rosa"

N.Vigoda Gonzales

Pragmatic Case Studies in Psychotherapy, http://pcsp.libraries.rutgers.edu

Volume 14, Module 1, Article 1, pp. 1-57, 09-12-18 [copyright by author]

Rosa: (Silence) I can't get go there... I can't feel for myself...

Nicole: (Realizing she is struggling to feel compassion toward herself) Because I can tell you something. If I was in that room and I saw a mother talking to her child like that, I would go to that little child, hold her and tell her: "Don't you listen to her, you're beautiful," and I would turn to that mother and say "How can you say that to her? Do you know how much pain you are causing her?" anticipatory mirroring]

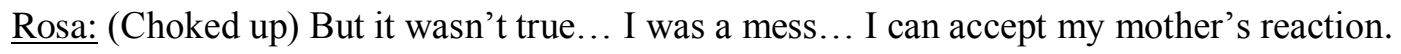

Nicole: It makes me very angry... maybe I am feeling the anger that you don't allow yourself to feel...

Rosa: I think the only way to get through this is to not feel [ready to move to defensive avoidance].

Nicole: What is it like for you to hear me say what I would do? To hear me say that it just makes me so angry?

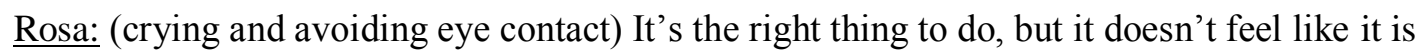
the appropriate thing for me to do....

Nicole: It is really hard to take it in.... Even now, when you acknowledge that there are other alternatives, that parents can treat their kids kindly, you seem to really struggle to feel compassion for yourself... There is such a big wall....

Rosa: Right now, this is as far as I can go.... and I think the only reason I can talk about these things now is because my mother passed.... I think that otherwise I would not.

An important shift began to happen in the next few sessions. Gradually, Rosa appeared more and more receptive of my affirmations and more able to experience pride in and admiration for herself, as well as anger and indignation in response to being neglected and abused. At the very beginning of session 15, Rosa described thinking in a "productive way" outside of sessions about our work in therapy, a sign that a growing capacity for self-reflection and internalization were developing. In between sessions, Rosa had identified moments in her childhood in which she recognized the unfair treatment and emotional impoverishment, and ways in which she tried to compensate for the lack of attention and affirmation. She called these moments her "secret life," which she had never shared with anyone. Rosa described cleaning the house and doing chores in her mother's absence to make her life easier; she relayed pursuing her first communion on her own with no family support; she recalled being encouraged by her school teacher and principal to take the High School Test at one of New York's elite, specialized high schools; and eventually skipping a grade after being placed in a specialized high school. Only now was Rosa stunned by the absolute lack of acknowledgement of all her achievements:

Now I realize and... Oh my goodness! I've been thinking about all the things I did that were impressive, and how nobody acknowledged them! Nobody cared! 
On the contrary, her family's reaction was indifference, ridicule, or the intense resentment and envy of her siblings.

Thus it appeared that Rosa was taking in my presence and affirmations, and beginning to actually experience in her own flesh glimmers of core affective experience (Gleiser et al., 2008), including pain, anger, and compassion for herself. Consistent with AEDP, I aimed at focusing the therapeutic attention on these experiences by mirroring and amplifying these glimmers of emotion. We engaged in cycles of meta-processing my affirmative remarks (e.g., "I think it's absolutely outstanding, all these things you did as a little girl"). While Rosa's initial responses exhibited her characteristic struggle in taking in this praise, (e.g., "I can't get comfortable there... I have to keep moving... I've never felt pride about these things... I never wanted to get noticed because I didn't want to provoke anyone, their envy or jealousy"), ultimately she was able to say:

Seeing your reaction makes me realize, wow! I was doing pretty great for a little girl under those circumstances! ... I'll tell you... it's very good... it's like finally there is someone who is sharing my experience... finally there is someone who was watching what I was doing, and saying, "Yes, I see it too."

As Rosa got emotionally connected with this experience, she offered insight into her depressive symptoms, stating that she finally understood they originated from a place within where she felt undeserving of any attention, admiration, or love. This led her to connect to her regret and sadness about the strained relationship with her siblings. She elaborated on her countless attempts to "fix" the relationship with her family, to belong, to be accepted, always thinking that it was her fault, that there was something wrong with her. I shared my indignation and asked her to process what it was like for her to hear me say this. It was only now, she said, that she realized there was "nothing wrong" with her. I asked her to repeat this statement:

Nicole: Can you say that again?

Rosa: (timidly) There is nothing wrong with me... I was so [ready to move away from the experience].

Nicole: Can you say that again?

Rosa: (voice breaking) There isn't anything wrong with me

Nicole: One more time... say it again.

Rosa: There isn't anything wrong with me! There isn't this huge lack of whatever it takes.

Nicole: Wow... What is it like to hear you say this?

Rosa: (with an exhilarated tone) It is very rare... I had always thought it was me... It's not about me! 
Competence Strategies in the Treatment of Relational Trauma: The Case of "Rosa"

N.Vigoda Gonzales

Pragmatic Case Studies in Psychotherapy, http://pcsp.libraries.rutgers.edu

Volume 14, Module 1, Article 1, pp. 1-57, 09-12-18 [copyright by author]

This marked a budding sense of self-worth, a genuine questioning of her sense of inadequacy, and a developing awareness of a maladaptive cycle of relating to her family based on this false image of herself. Moreover, this was in line with the goal of providing her with a new understanding of herself and of how subjugating her needs, while adaptive once, was now leaving her feeling inadequate, and inviting others to step over her. She could now recognize her inner strength and her ability to use it.

As the treatment progressed and we approached the end of the middle phase of treatment, important changes began to take place. Rosa began, and finished, each session by expressing positive feelings toward therapy: e.g., "I am so glad I'm coming here," "I feel invigorated as I'm getting ready to come here," and "This has been so helpful... It's like I'm finally seeing things clearly"). In addition, she exhibited signs of a healthy attachment toward me. As painful and uncomfortable as it was to experience the pain, hurt, and anger that was connected to the realization of her relational trauma, Rosa's confidence in her ability to handle such intense affect was growing. Furthermore, the gains in therapy were generalizing to Rosa's life outside of therapy.

In session 16, Rosa appeared invigorated, and reported that she wished to go out of her way to connect to people and to do things for herself. She reflected on how the positive experience in therapy had encouraged her to search for other experiences outside of therapy. I understood these new feelings as being the result of Rosa's opportunity to experience a new type of relationship through our therapeutic connection. Through these new relational experiences, Rosa had, for the very first time, the chance to experience someone as genuinely interested in what she had to say, while deeply connected to and engaged with her emotionally. In line with AEDP's assumption (Gleiser et al., 2008) that it is not sufficient that attachment operate implicitly, but rather that the patient's experience of the attachment relationship needs to be a major focus of the therapeutic work, I made a conscious effort to examine Rosa's receptive affective experience (Fosha 2000, 2006). Thus, I focused on helping her reflect on whether and how she had felt seen, helped, and/or understood in the therapy, and how this was connected to the changes she was noticing in herself. I asked Rosa to reflect on the aspects of our work that she thought were helping her.

Rosa: (In a bright tone) I think being able to describe something and seeing your reaction to it is like putting it in a more real context. It is like shining a light to what is actually happening right there, and you see it differently than you experienced it... I can say, "That wasn't right, it wasn't the right thing for that person to say to that child at that time!," and once you begin to see it through someone else's eyes, you begin to let go of the uncertainty of why those things happened, let go of the possibility that it was your fault, you can just let go of the feeling of being overwhelmed... And then you let go of that burden.

As we continued to deepen the affect associated to this new relational experience of a safe and healthy attachment, it became evident that Rosa was internalizing the idea that there was "nothing wrong" with her, and had caught herself repeating these words to herself in circumstances in which she started to feel put down by others. This internalization resulted in a more present, less reactive sense of self in relating to others, and while she acknowledged still getting upset in interactions with her sister, Rosa was no longer feeling bewildered, confused, 
and overwhelmed. With budding awareness about the ineffectiveness of subjugating her needs to sustain a relationship, Rosa was expressing in therapy a wish to give up her role of wanting to "fix" the relationship with her sister and the rest of her siblings. Instead, she understood that she could relate to others and maintain connections "without the mess." The imagery she presented was powerful: "I don't feel so overwhelmed because I am no longer beat up." And the realization that the idealized image of the relationship with her siblings - i.e., caring, nurturing, and respectful-was not realistic, was no longer devastating. For the first time Rosa was starting to feel as if she could let go of her efforts to try to figure out why the relationship with her siblings had become so strained after her mother's death. This marked an emerging sense of clarity about who she was.

In addition to Rosa's increased confidence in her ability to handle difficult interactions with her family, there were changes in her perception of that "space" she had started to feel as she became aware of her son's maturity and independence. As she elaborated on her son's progress (he was now attending his own therapy and exhibiting improvement), Rosa described feeling both a sense of relief as well as sadness about not playing the same role in his life. Whereas a month ago Rosa experienced herself as "sinking" and "drowning" in this "space" cleared by such realizations, she could now connect to core feelings of sadness and grief. More importantly, she was also experiencing hope! A month ago she had expressed interest in attending a Reiki healing group, an activity that appealed to her, but was truly scared of interacting with other people. Now, she had made the decision to attend this workshop, and to become engaged in other activities that interested her. This represented a big leap from her initial absolute refusal to consider meeting new people and establishing new relationships.

As we reflected on this change, Rosa acknowledged that, while still apprehensive about the outcome of interacting with others, she was enthusiastic about the possibility. She then expressed being more likely to talk about her "fears" of intimacy, as talking about these with me was "very different than being all-alone." These were signs that the relational safety was allowing her to access and process emotions that had previously been overregulated or dissociated, as well as to reduce her avoidance of intimacy by experiential focusing on the emotional nature of the therapeutic relationship (Fosha, 2000). They were also signs that the therapeutic work was successful at achieving its ultimate goal, undoing aloneness.

Rosa returned to our next session (session 17) after a last minute cancellation the prior week. While apologetic, she had a big smile on her face as she said to me: "I'm so sorry I missed last session, but I think you're going to be happy to hear why I didn't come." She told me that she had "made a friend" and had visited her prior to our session. She was having such a nice time, she said, that she lost track of time until she realized it was too late to make it to our appointment. "I was doing therapy outside of therapy!" added Rosa as we laughed together. While my typical stance as a therapist would be to interpret such a scenario as resistance, I understood this differently, particularly in the context of our recent explorations of Rosa's budding curiosity to connect to new people. I applauded her efforts and shared my genuine happiness at learning such news. 
During the same session, Rosa offered insight into the psychogenic nature of some of her somatic complaints. She reported worsening back pain, which she attributed to psychological distress. As she discussed the intensity of the pain, Rosa mentioned how lying on the floor or any hard surface was the only thing that alleviated the pain. Her affect became visibly dysphoric, and she immediately associated this with a painful recollection. As a child, Rosa had to share a bed with her oldest sister (eight years her senior), the one with whom she was still in contact, and remembered how she used to get deliberately kicked by her while trying to sleep. Initially, Rosa would curl up into a fetal position trying to take as little space as she could in the bed, but eventually she ended up sleeping on the floor to avoid being kicked. The somatic pain was deeply connected to her psychic pain, and Rosa seemed more in touch with the many instances and many ways in which she felt mistreated by her sister.

For example, Rosa recalled that as a child, this sister used to hit her. Now, as an adult, the sister would hurt Rosa emotionally by dismissing her feelings, taking advantage of her, or simply rejecting her. Rosa was feeling increasingly ambivalent about maintaining the connection with this sister, as Rosa questioned the meaning of the sister's hurtful actions. A careful exploration of the origin of her pain revealed Rosa's interpretation of her sister's actions as signs that the sister did not truly care for her. While I challenged the definitiveness of such a belief, Rosa reflected on how, on the one hand, the hurt she experienced in response to her sister's mistreatment was indeed painful; yet on the other hand, it was not "crushing." The realization that she could tolerate such pain without feeling dysregulated, or without wanting to run away from it, made her feel "stronger."

Session 18 marked the end of the middle phase of treatment. Rosa continued to report improvements in her mood and anxiety, as well as a decrease in somatic symptoms after exploring the source of the back pain in the prior session. She was actively engaging in activities that she had previously enjoyed but had left aside, such as yoga and meditation, and felt enthusiastic about them. Additionally, Rosa was actively participating in the Reiki healing groups, and was developing a friendship with the Reiki therapist. I celebrated her efforts and willingness to take risks in seeking connections by stating that she had realized that not all relationships needed to end up in pain and that not everyone would hurt her. When she responded by saying that she was "so far from genuinely believing that," I reviewed in detail all the risks she had taken to connect to other people. "Thank you for spelling this out to me," she added, "because I am so new in this that is hard for me to assess that I am making progress in this area."

Rosa's progress was also manifested in an increased ability to experience and tolerate intense, painful affect. A decrease in her defensive avoidance was bringing her closer in touch with painful sentiments associated with her strained relationship with her siblings. As the session progressed, Rosa was once again in touch with the aching hopelessness that she had experienced in her constant attempts to "fix" things with her family. I offered an interpretation to connect her defenses to her attachment needs. I stated that these were her attempts to get her family members to show her that they cared for her and that she belonged, and to find a place within her family; but that she continued to be hurt and rejected in the process. She described this as a "compulsion," and I added that such "compulsion" was driven by a wish for things to be 
different. She followed by saying, "I think I finally reached the end of that," and described how she saw her mother's death as the end of the road, but how she had held on to the relationship with her oldest sister as "the last rope."

As we continued to explore this, Rosa was able to eloquently describe how our efforts in helping her get in touch with deep, intense feelings--and processing and understanding them-was giving her a sense of clarity that she never thought she would achieve. She then added, "I didn't realize... it's so crazy... I didn't realize that this is what I had to do..." In an intense wave of affective experiencing and exploration, Rosa continued to recall her endless efforts and energy invested into the relationships with her family by always doing something for them, and the subsequent pain that she felt. With deep sadness and grief she stated:

I'm ready to give that up... I feel like I'm giving up everything... I feel like I'm giving up my whole world... I can't believe it... I find it hard to believe.

This represented her willingness to relinquish her "growth-inhibiting defenses" (Fosha, 2000; i.e., subjugating her needs, playing the victim, and subordinating herself to others); and to risk new ways of feeling and interacting, despite the anticipated grief of mourning the family she always wished she had.

\section{Final Phase: Sessions 19 - 23}

The main focus during the final phase of treatment was on processing feelings of grief and loss in connection with Rosa's decision of letting go of trying to belong to her family in the way she once hoped for, as well as experiencing and processing feelings related to the upcoming ending of our work together. As the focus of the therapy moved slightly away from processing past familial trauma, Rosa appeared to feel less of a need to use Spanish, and consequently the switches in language became more sporadic. Each session during this phase, involved a review of the progress that Rosa had made, and a consolidation of those gains. Notably, most of the time Rosa spontaneously introduced this processing as we connected things that were happening in her relationship with her son and her oldest sister to insights she had developed throughout the course of therapy.

In the first few sessions of this final phase, Rosa wanted to focus on issues related to her son. Initially I interpreted this as a regression to her customary defensive avoidance, since we seemed to be moving away from the more intensive processing of the core affect associated with her familial trauma. Nonetheless, as we explored this material together I understood that Rosa was attempting to find a sense of clarity and mastery in the most precious and valuable relationship she had at the moment, that with her son; and that she needed to differentiate this relationship from the turbulent connection she had maintained with her siblings.

In session 19, Rosa described re-emerging fears of losing her son based on recent interactions in which she perceived him as distant. After relaying a remote history of conflict with her daughter-in-law that resulted in her son distancing from her for a period of time, Rosa accessed feelings of apprehension that this would reoccur. As she described her struggle in 
directly communicating her needs and feelings to him for fear of being dismissed, I shared with her my perception of her struggle in an effort to help her gain insight into the manifestation of maladaptive relationship patterns learned in her relationship with her siblings: "It seems that in order to preserve the relationship with him, you feel the need to sacrifice your own needs... And you end up constantly feeling dismissed and punished, just as you have with your siblings." In a reactive manner, Rosa stated her relationship with her son was "totally different" from her relationship with her family of origin. I sensed a hint of irritation and decided to check in with her, to provide her with the opportunity to reflect on a potential miss-attunement on my part. Rosa explained she felt protective of her relationship with her son, and therefore it was difficult to compare it to her relationship with her siblings. She expressed appreciation for my interest in clarifying her reaction to my statement.

As we continued to understand the differences between these relationships, Rosa connected once again to the deep pain and grief of mourning an idealized connection to her family. The most immediate manifestation of this transformation was occurring in her relationship with her oldest sister, the only one she was still in contact with. Eight years her senior, her sister had multiple medical problems and at times neglected her health. Rosa spoke about her longstanding efforts to remain connected to her, assuming a submissive role and feeling responsible for her well-being, and yet not getting much in return. Rosa relayed a dream in which her deceased brother in-law was consoling her and reassuring her she did not need to take care of her sister nor feel guilty about it. Notably, Rosa described identifying with this brother in-law who was also marginalized and treated with contempt by her sister.

While describing the waves of pain she was feeling as she mourned the connection to her family, Rosa repeated how tired she felt of her fruitless efforts, and stated she felt liberated and relieved to take a step back and no longer be that person in her family. This, she commented, was one of the most valuable accomplishments of our therapeutic work, and she was deeply grateful for it. As the session ended, Rosa stated, "Today is hard to take it that we only have four sessions left."

Rosa's first words in our next session were: "I've decided I want to spend the next four sessions talking about my son." I hypothesized this decision was in part triggered by her anxiety about termination, and I asked her to elaborate on her motivation behind this wish. "He is just not connecting with me... It makes me nervous for him, and makes me unhappy because I feel neglected," she responded. We engaged in affective exploration of recent developments in their relationship, which allowed Rosa to access feelings of anger in the context of his unresponsiveness and failure to follow up with promises to visit or call her. With indignation in her voice Rosa stated, "I want him to act like a son! That I have some importance in his life! I think I deserve that!"

This was an important shift in Rosa's ability to not only identify her emotions clearly and in the moment instead of feeling desperate, overwhelmed, and confused, but also to experience core affect (e.g., anger) without the need to defend against it. I shared my observations of her progress with her, and Rosa eloquently followed by noting the differences between this and past experiences in treatment; for the first time she had "made time and space" for herself, and this 
had allowed for an exploration and an emotional connection to her history of trauma. Revisiting this history, she added, helped her to organize her emotions, to feel clearer about the despair she was immersed in at the onset of therapy, triggered by his son's drinking and his lack of communication.

In line with relational and AEDP approaches, I guided Rosa through an intensive affective exploration of her recently reported anxiety in relation to her son, which revealed a deeper fear of being uncared for by him. I, then, invited her to consider a connection between feeling uncared for in her relationship with her son, and feeling uncared for in other relationships, particularly with her siblings. With an invigorated tone she said:

Yes! That is probably a really good description of why it is so hard for me to move on when he does this... But this time it's a lot clearer... I am not confused about it... Suddenly I was put into that space... And it is good because I can differentiate, and react differently! It evokes those feelings, and then you attach those feelings to this situation, but when you look at it you realize it's not about the same, and you may be mixing things up and that is not helpful!

This illustrated Rosa's ability to recognize that her relationship with her son was different from her relationship with her siblings, which helped her realize she did not need to fear his rejection. I applauded her insight, her capacity for self-reflection, and her willingness to be vulnerable with me.

Stronger consolidation of her other gains in therapy were taking place. Rosa highlighted how the "way we had been talking" had enabled her to "keep going farther" and "go to places that were painful and stay there." "I can't believe I've gotten to this place," she expressed with elation. This was a sign that her tolerance of intense affect had significantly increased, and that the relational safety (Fosha, 2000) had fostered a greater willingness to experience these feelings and see their adaptive potential.

Rosa continued to exhibit significant progress in the next few weeks. She was spontaneously drawing connections between her reactions to events happening in her son's life and her traumatic experiences related to his past gang involvement. Rosa realized the fear she was experiencing now was not based on reality (her son actually being in imminent danger), but on such traumatic experiences she had lived through back then as a child. In discussing her realization that, at times, she re-experienced some of these feelings, Rosa asked me for referrals in the event she was to get into "that terror place again" and needed help. She went on to clarify this was not a current concern, as she felt "in control and able to sort things out" on her own.

I understood her request as a reflection of appropriate anxiety evoked by termination. Nonetheless, I was also curious whether a desire to connect to another therapist upon the end of our work together was mobilized by Rosa's hesitancy to establish relationships outside of therapy. Tentatively, I wondered out loud about this possibility, and how, if accurate, this would be a disservice to her (if, indeed, Rosa was using therapy to meet this need for connection). To my surprise, Rosa pondered on my suggestion, and followed with a powerful reflection. She felt more prepared to relate to others than she ever did in the past, as she recognized her improved 
ability to be genuine in interactions with others. Her increased capacity to identify her emotions helped her feel "safer," and no longer in need to "shut down" because of "fear that something would happen" (e.g., being berated, rejected, humiliated). Rosa eloquently portrayed the impact that developing insight into her negative sense of self had on her: "I was buying into this point of view about me that kept me so inhibited and unsure of me, and it restricted me! I feel freer now!"

She continued by reflecting on the fact that she had turned her son into her "life project," which at that point she understood was no longer appropriate. Despite having mixed feelings about her new role as a mother, she felt at peace with it, no longer lost.

I can let go now... This is one of the biggest things that I have accomplished here; that it is his life, and I can be involved in a different way, no longer trying to fix things. As much as I value my son, I realize that there is more for me than focusing on him!

I was amazed and humbled by Rosa's words, and her insightful ability to delineate her progress. Consistent with AEDP, I shared my emotional reaction with her, my sense of pride and admiration. With excitement, she described a "budding curiosity" and "profound" excitement that were driving her to explore the world and do new things for herself (like the infant that in a safe relationship feels encouraged to explore), as opposed to the fear and self-doubt that had inhibited her for so long. She then offered a powerful image of what the experience of a safe attachment bond had provided for her:

I will tell you... what this experience with you has given me is an appetite for going out and looking for other relations, because now there is something "delicious" to look for in relationships.

This was a clear sign that a repair in her attachment had indeed taken place through our work together. Rosa further elaborated on the effects of this experience of secure attachment on her ability to be affectively present, and to use her emotions as a guide when interacting with others. In contrast to this, she had, for so long, felt "numb and unsure," always questioning whether it was she or her family who provoked the chaos, pain, and confusion. She could finally put an end to that, she stated. As we ended the $21^{\text {st }}$ session, Rosa expressed deep appreciation of the processing of therapy gains, as she felt it helped her integrate these into herself.

The following week Rosa returned and excitedly said,

You'd be very proud of me! I introduced myself to my new neighbor... It's like I'm getting out of my funk!

I tracked her affect and pointed out the excitement and joy that she exuded as she shared this news with me. Was it possible, I asked her, that she was also feeling proud of herself? Rosa timidly smiled as she responded affirmatively, and followed by stating that other important changes were taking place within her and in her relationship with her son. She was aware of how her recent reactions of fear and anxiety to her son's apparent distance were projections of her own insecurities in her relationships with her siblings. This awareness had helped her realize that her connection to her son was not as fragile as she had thought. Moreover, in a recent candid 
conversation she had with him about his turbulent past, he had openly acknowledged her unconditional love and support throughout that time. As I helped her explore the significance of this interaction, with tears in her eyes, Rosa explained how his recognition was validating, and she could allow herself to "really believe" that she had done everything in her power to be the best mother she could under the circumstances. I recognized an important shift was occurring as Rosa relinquished the guilt and self-blame (inhibiting affects) she had held onto for so long in this particular relationship with her son, and this opened the door to compassion toward herself. I guided her through the meta-processing of this state transformation (Fosha, 2000), as she acknowledged the ways in which she had been callous and uncompassionate toward herself.

The processing of these changes brought to the forefront Rosa's grieving of her family of origin. She was deeply connected to this experience in the moment, and although painful, there were no attempts on her part to move away from it. I commended her courage in facing these feelings, and she responded by stating she realized she was giving up the "nasty" parts, and not "something nurturing and good" for her. As I highlighted the fact that she was not only giving up the victimized role, but also the wish for things to be different, to be nurtured and attended to, and to be cared and respected, I decided to label the process as grieving and mourning. Rosa intently looked at me, and with tears in her eyes responded affirmatively,

Yes, yes. That is what it feels like. Is a deep wrenching sadness; it's something that I invested a great deal of emotion into, and always had it in my head that it was possible... and I lived with that picture instead of the real picture... It's like you're so desperate for things to be different that you don't realize how you're getting bitten up.

In line with AEDP's goal of undoing aloneness through dyadic regulation of affect (Fosha, 2000), I explicitly emphasized my presence and willingness to support and accompany her in this process of riding the waves of sadness and pain that she was experiencing. Not once did Rosa refer to this experience as "too painful" or "too overwhelming."

An important development as she continued to process her feelings of loss was her emerging willingness to acknowledge her "parents' limitations" and to become aware of her tendency to idealize them. Simultaneously, she recognized her difficulty in allowing herself to feel anger toward them, especially her mother, albeit stating she realized her mother "could have intervened and done more" to protect her. I applauded her budding awareness of such feelings, while at the same time respected her decision to not deepen them at that point. Instead, I opted to offer an interpretation that connected her avoidance of negative affect toward her mother to her fear that, if she were to give herself permission to feel such emotions, the connection she was able to establish with her in the final years of her life would be destroyed.

In response to my interpretation, Rosa acknowledged how her mother, despite the closeness they had established, once again became rejecting in the last few months of her life. I tracked her affect, and through somatic experiential techniques, assisted Rosa in connecting to the pain and despair she felt then. "Se me salio el Corazon," she said in Spanish (which means, "My heart came out of my chest") as her head hung low and she cried. 
Competence Strategies in the Treatment of Relational Trauma: The Case of "Rosa"

N.Vigoda Gonzales

Pragmatic Case Studies in Psychotherapy, http://pcsp.libraries.rutgers.edu

Volume 14, Module 1, Article 1, pp. 1-57, 09-12-18 [copyright by author]

She followed by vividly describing her efforts to revive the connection by resisting her impulse to "run away," and instead, remaining by her bedside, holding her hand until the very end. She switched to Spanish once more, and recalled the feeling of her mother's hand in her hand: "Estaba tibia y viva... muy viva" ("It was warm and alive, so alive"). As we engaged in the experiencing and processing of such experience, Rosa continued to switch to Spanish as she recalled the details of that last week by her mother's side. Rosa appeared to be deeply connected to the emotions evoked by such memories as she accessed them in the language she communicated with her mother. The vibrancy of her story was almost palpable, and she reflected on the meaning of her decision to stay by her mother's side despite her rejection: her mother was indeed grateful, and Rosa felt she had "repaired that loss." She was aware of the pain that her mother's rejection had inflicted, but had decided to hold on to a "sweeter" memory of their relationship. To this day, Rosa would watch telenovelas in Spanish (Hispanic soap operas) which they did together before she passed away — as a strategy to keep such bond alive.

The following week, in the final session (\# 23), Rosa announced without hesitation that she felt sad, sad that it was the last day of our work together. I shared her sentiments. Recognizing the importance of helping Rosa identify aspects of the treatment that were helpful in improving her mood and her ability to revisit traumatic memories without becoming overwhelmed, I decided to guide her through this process. Rosa beautifully portrayed the metamorphosis she had undergone, and once more, her clarity and insightfulness touched and impressed me.

When you realize that the key you've been looking for does not exist, and you realize that the search of that defect within you that explains all you suffering is nowhere to be found because it is not you... is... liberating... I have to tell you, I feel liberated.

Her words clearly captured a transformation in her sense of self. She had moved away from a deeply negative image, filled with guilt, shame, and self-doubt, and had accessed her "true-self" or "self-at-best" (Fosha, 2000). She followed by describing the impact of such inner transformation on her interpersonal life and role in relationships, both with her siblings and her son; as she expressed feeling "so happy" about her realization that she needed to "give up the attempt to fix things" with her siblings, she identified changes in her emotional response to them:

I feel so unmoved by that, so "aparte" [removed]. I don't feel the compulsion to connect with them; and with my sister, I can set boundaries."

She had "healed," Rosa added, and no longer felt "confused." Rather, she was aware that she had "sorted it out." She reflected on her ability to let go of the sense of responsibility and blame that she had so ferociously held onto to explain the escalating conflict with her siblings, and explained that, this had generalized to her relationship with her son: "I'm not scared anymore... and that amazes me." I mirrored her sense of accomplishment and celebrated it.

Consistent with AEDP, I understood these transformations that she so beautifully described as being fostered by the new relational and emotional experiences provided throughout the therapy. Further solidifying and consolidating of such experiences was crucial, and I wished to know how Rosa felt about her ability to maintain these gains. Thus, I encouraged her to 
process the impact of our relational experience by asking her what it had been like to go through all of these changes with me. Her response was powerful:

Well, I feel at this point that a lot of the work was completed. It's like when you heal a broken bone and you can keep walking. It's actually healed and you just can keep walking... I don't need to keep coming to keep it that way. What needed to be done is healed, is done, and I don't need to add more fuel to it because is running".

Then, following this, she spontaneously offered her imagery of what a safe attachment in the therapeutic relationship had been like for her. I helped her amplify this experience:

Rosa: I'll miss you... What you do when you listen and reflect back the things I say... What you do is like stepping into another world and I will miss that, I will miss seeing my world through your eyes, having someone else there with me [undoing aloneness]... Is like 'una claridad' ("a sense of clarity") that you bring into this...

Nicole: This is so powerful... I can see that as you say this, your eyes are teary.

Rosa: I'm really touched by having been able to open up to you, and having you reflect on it without it being painful; all of these terrible things, and when you talked about it, it wasn't harmful... Is like opening a curtain and a very soft sunlight comes in... That's how it was... I'll miss that kind of touch.

Nicole: I'm going to miss participating in that... I truly am...

Rosa: I'm just amazed and grateful for it... because I really didn't have the expectation that I would be able to change all that terrible stuff... And actually I thought it would take an incredible amount of work and time.

This vividly illustrates how a safety-engendering therapist-patient relationship based on the availability and responsiveness of the therapist counteracts pathogenic aloneness (Fosha, 2000; 2006). Deeply moved by Rosa's words, I followed with an emotional self-disclosure: 'I'm delighted to hear this... I'm moved by what you are saying... I'm delighted to hear that... It is so touching... it makes my heart warm." I then invited her to respond with an experiential elaboration of the receptive experience by asking her how she felt when she saw me moved by what she was saying. To this she responded,

I'm happy to hear that [with tears in her eyes]... It's good, I think I have a lot of good things to offer, and I think a lot of times it's hidden away, and to have affected somebody in a good way and to hear it is so nice... To have someone that has something good to say about me is wonderful... that is something that I needed very badly... it's a wonderful experience.

This ability to genuinely take in my affirmation represented a substantial change in Rosa's capacity for establishing intimacy, as she was able to receive my statement without feelings of shame or guilt. 
As we were close to saying our final good-bye, Rosa looked at me intently and emphasized how "special" it was for her to be able to work with someone whose first language was also Spanish. She added:

It wasn't that I didn't know how to communicate in English, but there is always something that when you say it, it connects differently, and I think that was a very good thing... I'm grateful for that too.

This was a testament that Rosa's opportunity to use her mother tongue in sessions had helped her experience emotions vividly and strongly, and had fostered a stronger connection between us. I felt humbled and gratified that Rosa had given me the opportunity to enter into her world and accompany her in her growth. At the end of the session, we embraced, and in my mind this symbolized the power of our therapeutic relationship.

\section{THERAPY MONITORING AND USE OF FEEDBACK INFORMATION}

The treatment with Rosa was monitored on a weekly basis through individual supervision with my direct supervisor of the case. During these weekly meetings, my supervisor and I reviewed and discussed in detail the DVD recording of each prior session. This involved an indepth analysis of Rosa's needs and her responses to interventions, which led to the required adjustments in conceptualization and treatment plan implementation. The ongoing weekly supervision was especially helpful in allowing for continuous tracking of Rosa's progress and a fluid development of an individualized treatment plan designed to meet her needs at each stage of our work together. My supervisor's training in AEDP and extensive experience in treating patients with trauma was an invaluable asset in addressing Rosa's history of relational trauma.

In addition to this, I utilized Rosa's case as the applied portion of a yearlong graduate course in Short-Term Psychodynamic Therapy, and thus had the opportunity to present on a few occasions DVD recordings of our session to my peers and class instructor (who happened to be my supervisor on the case). These experiences were incredibly helpful in yielding critical feedback and a fruitful discussion related to Rosa's progress. At times, these discussions challenged some of my preconceived notions and allowed for adjustments in style and/or intervention.

Finally, I also used one clinician-rated measure, the Hamilton Depression Rating Scale (HDRS), and two self-report measures, the Trauma Symptom Inventory - 2 (TSI-2) and Outcome Questionnaire (OQ-45) to track Rosa's progress. I completed the HDRS based on Rosa's initial presentation and at termination. As mentioned above in section 4, Rosa filled the TSI-2 and the OQ-45 during our follow-up session. At my request, since I did not have the chance to use these at the beginning of her treatment, she completed another set of these measures based on her recollection of her symptoms at the onset of therapy. Thus, again, albeit not the standard, valid way of administering these questionnaires, it provides Rosa's subjective evaluation of her progress from the start to the end of treatment. Notably, the results yielded by these two measures are consistent with Rosa's clinical presentation at intake. 


\section{CONCLUDING EVALUATION OF THE THERAPY'S PROCESS AND OUTCOME}

Rosa's progress in treatment was steady, ultimately leading to a favorable outcome. Various indicators, which are presented below, support this positive outcome. By the end of treatment, and at 3-month follow-up, Rosa's depressive and anxiety symptoms had decreased, and her overall and interpersonal functioning had improved. Her willingness to engage in what proved to be emotionally challenging work was an important contributor to the success of treatment. Finally, I believe our shared bilingualism and ethnic similarities strengthened our therapeutic alliance, and enhanced Rosa's ability to experience intense emotions associated with her familial trauma.

\section{Quantitative Results}

Table 2 presents the changes in Rosa's score on the Hamilton Depression Rating Scale (HDRS). As can be observed, Rosa's score at the beginning of treatment was 30, in the "very severe" range of depression, and decreased to a score of 8 at termination, in the "mild" range of depression. This change in the total score indicates a clinically meaningful decrease in Rosa's depressive symptoms.

Table 4 summarizes the changes in Rosa's scores on the Trauma Symptom Inventory - 2 . As the table illustrates, from the 13 scores that were initially clinically elevated (i.e., above 64 or 1.5 standard deviations above the mean), 11 decreased to the normal range (i.e., below 60), and two to the problematic range (i.e., between 60 and 64). It is notable that although one of these two, the Anxiety subscale, did not decrease to the normal range, the change in score in this subscale was statistically significant. Additionally, all four scores that were initially problematic fell below the clinical norm at termination. The significant decrease in most scales, subscales, and factors described above, indicate a clinically meaningful reduction of Rosa's PTSD-like symptoms.

Table 5 depicts the changes in Rosa's scores on the OQ-45. At the onset of treatment, three OQ-45 subscales - Total Score, Symptom Distress, and Interpersonal Relations - were above the clinical cut-off. At the end of treatment, two out of these three scores (Total Score and Symptom Distress) fell below the clinical cut-off point, and one was right at the cut-off point (i.e., Interpersonal Relations). It is notable that the decrease in all three scores exceeded statistical significance on Jacobson and Truax's (1991) Reliable Change Index (RCI). Again, these changes are indicative of a clinically meaningful reduction in symptoms of anxiety, depression, somatic problems, and stress.

\section{Qualitative Results}

As described above in section 6, Course of Treatment, throughout the last five sessions, Rosa and I reviewed and reflected upon the gains she had accomplished in therapy. These are summarized below: 
- Rosa was no longer feeling the overwhelming despair, confusion, panic, and anxiety with which she presented at the onset of treatment. On the contrary, she was able to experience and better tolerate negative feelings without becoming paralyzed and/or immediately resorting to avoidance. By the end of treatment, Rosa was able to use these feelings adaptively, as organizing experiences. For instance, in the last few sessions she felt angry toward her son's unresponsiveness and failure to follow-up, and she openly expressed her indignation toward him as she felt deserving of a better reaction from him.

- Rosa's relationship with her son improved, and she felt more empowered to talk to him about her concerns, while also understanding her limits as a parent of an adult man. She gained tremendous insight into maladaptive relationship patterns. Rosa was able to differentiate her relationship with her son from her relationship with her siblings, and not feel so threatened when conflict with him emerged.

- Rosa had moved away from a deeply negative self-image of a powerless, worthless person, and accessed positive feelings toward herself. This, she reported, made her feel "liberated" and freed from the role of victim with which she had identified for so long. As a result, she felt empowered to set appropriate boundaries rather than to feel scared.

- Rosa was now more compassionate toward herself, and experienced less guilt and shame. With this transformation, Rosa was able to see the abuse and neglect she suffered for what it was, rather than blame herself. She also allowed herself to believe that she had done everything in her power to be the best mother she could under the circumstances.

- Rosa was entertaining with excitement the idea of meeting people and creating new friendships. She had taken some steps in that direction, and had made a few connections. This was in stark contrast to how she presented at the beginning of treatment, when she perceived all potential relationships as threatening. Albeit still slightly wary about the potential consequences, Rosa felt less inhibited and more open to meeting new people.

- Rosa had achieved an increased sense of calmness, peacefulness, and contentment. She experienced less tension, anxiety, and somatic complains.

Based upon the quantitative and qualitative results presented above, it appears that Rosa was able to meet a vast majority, if not all, of the goals described above in section 5, Case Formulation and Treatment Plan:

GOAL 1: To increase Rosa's sense of relational safety and trust in the therapeutic relationship

GOAL 2: To develop Rosa's insight into her defenses against closeness

GOAL 3: To increase Rosa's ability to tolerate intense affect

GOAL 4: To help Rosa relinquish her defenses against the experience of affect 
Competence Strategies in the Treatment of Relational Trauma: The Case of "Rosa"

N.Vigoda Gonzales

Pragmatic Case Studies in Psychotherapy, http://pcsp.libraries.rutgers.edu

Volume 14, Module 1, Article 1, pp. 1-57, 09-12-18 [copyright by author]

\section{GOAL 5: To process adaptive emotions to completion}

GOAL 6: To improve Rosa's sense of self

\section{GOAL 7: To reduce Rosa's hypersensitivity to rejection and avoidance of social interactions}

\section{GOAL 8: To alleviate Rosa's depressive and PTSD-like symptoms}

In summary, Rosa experienced several changes from the beginning to the end of our work together, which she had maintained by our follow-up session. Her PTSD-like and depressive symptoms had decreased and were no longer affecting her on a day-to-day basis. She was able to genuinely connect with me as her therapist, and to experience trust and safety with another human being. Her capacity to tolerate intense affect in the here-and-now increased tremendously, and for the first time, she was able to process the complex traumatic experiences of her childhood abuse and neglect, and understood their impact on her distress. She grieved the passing of her mother. Her sense of self dramatically improved, and she was able to relate to others more genuinely and comfortably. Her relationship with her son deepened, and she relinquished her need to control him. Rosa was also able to understand her family's limitations, which gave room to a sense of relief, and an increased capacity to experience enjoyment.

\section{Discussion of the Broader Issues Raised by Rosa's Case}

\section{Complex PTSD Versus PTSD From a Single Traumatic Incident}

Despite controversy around the construct of Complex PTSD, there is consensus in the literature regarding the differences in clinical presentation between survivors of a single traumatic event who develop PTSD, and survivors of multiple and recurrent traumatic experiences. Whereas the former generally show a narrow range of anxiety dominated symptoms, the latter tend to exhibit additional disturbances in affective dysregulation, negative self-concept, and interpersonal problems (Cloitre et al., 2013). These individuals typically present with severe, pervasive, and multifaceted problems, and more severe functional impairment (Jonkman et al., 2013).

These differences in symptomatology between PTSD and Complex PTSD introduce particular challenges into therapy. Examining side-by-side case studies of the treatment of trauma sequelae from single versus multiple incidents allows for an appreciation of the challenges that clinicians may encounter in working with one population versus the other, particularly when similar models are used. My treatment with Rosa, on the one hand, focused on addressing the complicated forms of emotional dysregulation, attachment disturbances, entrenched defenses, and dissociative symptoms characteristic of survivors of chronic relational trauma. An attachment-based, experiential approach like AEDP proved to be helpful in tackling these issues. On the other hand, Pass (2012) used a combined approach of AEDP (Fosha, 2000) with expressive writing (Calhoun \& Resick, 1993) to treat "Grace," a 24-year-old woman who developed PTSD after a single traumatic incident, finding the body of her brother who 
committed suicide. While AEDP helped lay the groundwork for a secure working alliance, familiarize Grace with affective exploration, and prepare Grace for deeper exploration of the trauma, the second phase focused on using expressive writing to directly expose Grace to the index trauma and help her process it to completion (Pass, 2010).

The treatments of Grace and Rosa highlight the qualitative differences in what clinicians may face when addressing the havoc caused by a single traumatic incident versus multiple and recurrent events. In the case of Grace, while even the prospect of revisiting the trauma through the writings evoked immense distress for the patient, there was a clear target and a narrower range of triggering stimuli. In contrast, in working with Rosa, the triggering stimuli were more diffuse, as is the case when working with chronic exposure to multiple trauma and its resulting sequelae. My experience as a clinician metaphorically resembled walking on a minefield; there was a higher probability of stepping on the "wrong" place, which could throw the patient into a state of dissociation or dysregulation.

Additionally, the attachment disturbances caused by a chronic exposure to relational trauma called for a steadfast focus on building relational safety through new attachment experiences and engendering a sense of trust. In Pass's case study, Grace's premorbid capacity to trust and rely on supportive figures like her husband, although dampened by the trauma, was solid enough to allow for a reestablishment in equilibrium. The role of the AEDP-informed clinician was to repair and strengthen such capacity, as the symptoms of PTSD gradually subsided. On the other hand, in my work with Rosa, our relationship was in fact her first experience of a secure attachment, and as such, part of the work consisted in taking risks in testing this experience in other relationships outside of therapy. This was indeed a slower and more laborious exercise, and may explain some of the ongoing interpersonal difficulties that Rosa continued to present at the end of treatment, despite the tremendous improvement.

Although the limitation of space does not allow me to do justice to Pass's (2010) case study, I hope that this brief comparison illustrates some important points to consider in the treatment of each of these patient groups. Whereas the literature seems clearer on the treatment guidelines for PTSD from a single traumatic event, with a short-term, trauma-focused approach considered the gold standard, there is still less consensus when it comes to the treatment guidelines for Complex PTSD. Nonetheless, our patients also teach us what they need, and as clinicians, it is our responsibility to recognize the importance of delivering flexible, patienttailored treatments that match the complexities of their presenting issues.

\section{Lessons Learned About AEDP With Bilingual Patients From Rosa's Case}

My work with Rosa brought to the forefront of my attention the intricate and crucial role that our patients' cultural identities play in psychotherapy, especially their language. This is particularly relevant when it comes to the treatment of trauma, and even more so with AEDP, where experiencing and processing of emotions is fundamental to recovery. In the case of Rosa, it was clear to me that a drastic change in her attitude toward the therapy and her ability to 
experience affect associated with her traumatic memories occurred after I disclosed my shared bilingualism. While most of our work continued to be in English given the context of the treatment, i.e., the case was assigned as part of a doctoral clinical psychology course on Short Term Dynamic Psychotherapy, my invitation to switch to Rosa's mother tongue opened a window to a separate stream of associations and levels of emotionality that may have not been accessed had I decided to conceal my own identity as a bilingual person.

There are, of course, some limitations to this case study and the conclusions one can derive from it. First, I would ensure in the future a timely administration of the quantitative measures used in this case study. This would provide a more accurate assessment of Rosa's clinical presentation pre- and post-treatment, rather than only her subjective experience of her symptoms. There are also limitations to the extrapolation of the perceived enhancement effects that incorporating bilingualism can have on the implementation of AEDP or any other psychotherapeutic approach. To start with, this case study is based only on one single patient, and no generalizations can be directly made to the general population. Additionally, it would be important in the future to introduce a measure of therapeutic alliance and emotional processing preceding the invitation to switch to the mother tongue as well as afterward. This would assess for changes in the level of relational safety and experiencing of affect that the patient may or may not have felt as a result of the language switch.

Lastly, other questions worth exploring are whether or not the clinician's level of proficiency in the patient's mother tongue is sufficient to effect change, or whether ethnic matching introduces an additional benefit to the experience of relational safety. It is also important to add that although there are benefits to a shared bilingualism, and potentially a shared ethnic identity between patient and therapist, these are by no means requirements for the establishment of a secure therapeutic alliance and a successful outcome in treatment. It must be kept in mind that several other issues operate in the relationship between patient and therapist that may be of equal or greater importance in determining the strength of the relationship and the success of treatment. Hence, I describe in detail the case of Rosa with the hope that its nuances and specificity generate further reflections on the cultural dimensions of psychotherapy.

\section{REFERENCES}

American Psychiatric Association: Diagnostic and Statistical Manual of Mental

Disorders, Fourth Edition, Text Revision. Washington, DC, American Psychiatric Association, 2000.

Ainsworth, M.D.S., Blehar, M.C., Waters, E., \& Wall, S. (1978). Patterns of attachment: A psychological study of the strange situation. Hillsdale, NJ: Erlbaum.

Bowlby, J. (1973). Attachment and loss: Vol. 2. Separation. New York: Basic Books.

Bowlby, J. (1980). Attachment and loss: Vol. 3. Loss, sadness, and depression. New York: Basic Books.

Bowlby, J. (1982). Attachment and loss: Vol. 1. Attachment (2d ed.) New York: Basic Books. Briere, J. (2011). Trauma Symptom Inventory, 2nd ed. (TSI-2) professional manual. Odessa, FL: Psychological Assessment Resources.

Briere, J., Kaltman, S., \& Green, B. L. (2008). Accumulated childhood trauma and symptom 
complexity. Journal of Traumatic Stress, 21(2), 223-226.

Buxbaum, E., (1949). The role of the second language in the formation of the ego and superego. Psychoanalytic Quarterly, 18, 279-289.

Byford, A. (2015). Lost and gained in translation: The impact of bilingual clients' choice of language in psychotherapy. British Journal of Psychotherapy, 31(3), 333-347.

Cabral, R. R., \& Smith, T. B. (2011). Racial/ethnic matching of clients and therapists in mental health services: A meta-analytic review of preferences, perceptions, and outcomes. Journal of Counseling Psychology, 58(4), 537-554.

Chao, P. J., Steffen, J. J., \& Heiby, E. M. (2012). The effects of working alliance and clientclinician ethnic match on recovery status. Journal of Community Mental Health, 48, 9197.

Clauss, C. S. (1998). Language: The unspoken variable in psychotherapy practice. Psychotherapy, 35(2), 188-196.

Cloitre, M., Gavert, D. W., Brewin, C. R., Bryant, R. A., \& Maercker, A. (2013). Evidence for proposed ICD-11 PTSD and complex PTSD: A latent profile analysis. European Journal of Psychotraumatology, 4: 20706, doi: http://dx.doi.org/10.3402/ejpt.v4i0.20706

Cloitre, M., Gavert, D. W., Weiss, B., Carlson, E. B., \& Bryant, R. A. (2014). Distinguishing PTSD, Complex PTSD, and Borderline Personality Disorder: A latent class analysis. European Journal of Psychotraumatology, 5: 25097, doi: http://dx.doi.org/10.3402/ejpt.v5.25097

Cloitre, M., Stolbach, B. C., Herman, J. L., van der Kolk, B., Pynoos, B., Wang, J., \& Petkova, E. (2009). A developmental approach to Complex PTSD: Childhood and adult cumulative trauma as predictors of symptom complexity. Journal of Traumatic Stress, 22(5), 399-408.

Damasio, A.R. (1999). The feeling of what happens: Body and emotion in the making of consciousness. New York: Harcourt Brace.

Davanloo, H. (Ed.). (1980). Short-term dynamic psychotherapy. New York: Jason Aronson.

Ford, J. D. (2005). Treatment implications of altered affect regulation and information processing following child maltreatment. Psychiatric Annals, 35(5), 410-419.

Fosha, D. (2000). The transforming power of affect: A model for accelerated change. New York: Basic Books.

Fosha, D. (2002a). Trauma reveals the roots of resilience. Constructivism in the Human Sciences, 6 ( $1 \&$ 2), 7-15. Special September $11^{\text {th }}$ issue.

Fosha, D. (2002b). True self, true other and core state: Toward a clinical theory of affective change process. Paper presented at the Los Angeles Psychoanalytic Society and Institute, Los Angeles, February 28, 2002.

Fosha, D. (2003). Dyadic Regulation and Experiential Work with Emotion and Relatedness in Trauma and Disorganized Attachment In M.F. Solomon \& D.J. Siegel (Eds.), Healing trauma: Attachment, mind, body, and brain, (pp.221-281). New York: W.W. Norton \& Company.

Fosha, D. (2004). 'Nothing that feels bad is ever the last step:' The role of positive emotions in experiential work with difficult emotional experiences. Clinical Psychology and Psychotherapy, 11, 30-43. 
Fosha, D. (2006). Quantum transformation in trauma and treatment: Traversing the crisis of healing change. Journal of Clinical Psychology, 62, 569-583.

Fosha, D., \& Yeung, D. (2006). AEDP exemplifies the seamless integration of emotional transformation and dyadic relatedness at work. In G. Stricker \& J. Gold (Eds.), A casebook of integrative psychotherapy (pp. 165-184). Washington, DC: APA Press.

Gleiser, K., Ford, J. D., \& Fosha, D. (2008). Contrasting exposure and experiential therapies for complex posttraumatic stress disorder. Psychotherapy Theory, Research, Practice, Training, 45(3), 340-360.

Gowrisunkur, J., Burman, E., \& Walker, K. (2002). Working in the mother-tongue: First language provision and cultural matching in inter-cultural therapy. British Journal of Psychotherapy, 19(1), 45-58.

Greenberg, L.S., \& Safran, J. (1989). Emotion in psychotherapy. American Psychologist, 44, 1929.

Greenson, R. R. (1950). The mother tongue and the mother. International Journal of PsychoAnalysis, 31, 18-23.

Harris, C.L. (2010) Bilingual speakers in the lab: Psychophysiological measures of emotional reactivity. Journal of Multilingual and Multicultural Development 25: 223-47.

Herman, J. L. (1992a). Complex PTSD: A syndrome in survivors of prolonged and repeated trauma. Journal of Traumatic Stress, 5, 377-391.

Herman, J. (1992b). Trauma and recovery: The aftermath of violence-from domestic abuse to political terror. New York: Basic Books.

Jonkman, C. S., Verlinden, E., Bolle, E. A., Boer, F. \& Lindauer, R. J. (2013). Traumatic stress symptomatology after child maltreatment and single traumatic events: different profiles. Journal of Traumatic Stress, 26(2), 225-232.

Karlsson, R. (2005). Ethnic matching between therapist and patient in psychotherapy: an overview of findings, together with methodological and conceptual issues. Cultural Diversity and Ethnic Minority Psychology, 11(2), 113-129.

Kokaliari, E. (2011). Alien to this country. Treatment considerations with bilingual immigrant patients. In J. Berzoff (Ed.), Falling through the cracks. Treatment with vulnerable oppressed populations (pp. 372-396). New York, NY: Columbia University Press.

Kokaliari, E., Catanzarite, G., \& Berzoff, J. (2013). It is called mother tongue for a reason: A qualitative study of therapists' perspectives on bilingual psychotherapy - treatment implications. Smith College Studies in Social Work, 83(1), 97-118.

Kohatsu, E. L., Dulay, M., Lam, C., Concepcion, W., Perez, P., Lopez, C., \& Euler, J. (2000). Using racial identity theory to explore racial mistrust and interracial contact among Asian Americans. Journal of Counseling \& Development, 78, 334-342.

Lambert, M. J., Kahler, M., Harmon, C., Burlingame, G. M., \& Shimokawa, K. (2011).Administration \& scoring manual for the Outcome Questionnaire-45.2. Salt Lake City: OQMeasures.

Levenson, H. (1995). Time-limited dynamic psychotherapy: A guide to clinical practice. New York: Basic Books.

Lipton, B., \& Fosha, D. (2011). Attachment as a transformative process in AEDP: Operationalizing the intersection of attachment theory and affective neuroscience. Journal of Psychotherapy Integration, 21(3), 253-279. 
Maercker, A., Brewin, C. R., Bryant, R. A., Cloitre, M., Reed, Van Ommeren, M., et al. (2013). Diagnosis and classification of disorders specifically associated with stress: proposals for ICD-11. World Psychiatry, 12(3), 198-206.

Marian, V. \& Kaushanskaya, M. (2004) Self-construal and emotion in bicultural bilinguals. Journal of Memory and Language 51: 190-201.

Marian, V. \& Neisser, U. (2000) Language dependent recall of autobiographical memories. Journal of Experimental Psychology: General 129: 361-8.

Messer, S. B., \& Warren, C. S. (1995). Models of brief psychodynamic therapy: A comparative approach. New York: Guilford Press.

Panksepp, J. (1998). Affective neuroscience: The foundations of human and animal emotions. New York: Oxford University Press.

Paradis, A. (1994) Neurolinguistic aspects of implicit and explicit memory. Implications for bilingualism and SLA. In: Ellis, N. (ed.), Implicit and Explicit Learning of Languages. San Diego, CA: Academic Press.

Pass, E. R. (2012). Combining expressive writing with an affect- and attachment-focused psychotherapeutic approach in the treatment of a single-incident trauma survivor: The case of "Grace." Pragmatic Case Studies in Psychotherapy, 8(2), Article 1, 60-112. Available: http://pcsp.libraries.rutgers.edu, http://dx.doi.org/10.14713/pcsp.v8i2

Pavlenko, A. (ed.) (2006) Bilingual Minds. Emotional Experience, Expression and Presentation. Clevedon: Multilingual Matters.

Perez-Foster, R. (1992). Psychoanalysis and the bilingual patient: Some observations on the influence of language choice in the transference. Psychoanalytic Psychology, 9, 61-76.

Perez-Foster, R. (1996). The bilingual self: Duet in two voices. Psychoanalytic Dialogues, 6, $141-150$

Perez Rojas, A. E., Gelso, C. J., \& Bhatia, A. (2014). To switch or not to switch: Inviting bilingual clients to switch languages in psychotherapy. Counseling Psychology Quarterly, 27(1), 55-74.

Russell, E., \& Fosha, D. (2008). Transformational affects and core state in AEDP: The emergence and consolidation of joy, hope, gratitude, and confidence in (the solid goodness of) the self. Journal of Psychotherapy Integration, 18(2), 167-190.

Santiago-Rivera, A., Altarriba, J., Poll, N., Gonzalez-Miller, N., \& Cragun, C. (2009). Therapists' views on working with bilingual Spanish-English speaking clients: A qualitative investigations. Professional Psychology: Research and Practice, 40, 436-443.

Schnyder, U. (2005). Why the new psychotherapies for posttraumatic stress disorder? Psychotherapy and Psychosomatics, 74, 199-201.

Schore, A.N. (1994). Affect regulation and the origin of the self: The neurobiology of emotional development. Hillsdale, NJ: Erlbaum.

Schore, A. N. (2001). The effects of early relational trauma on right brain development, affect regulation and infant mental health. Infant Mental Health Journal, 22, 201-269.

Schrauf, R. W. (2000). Bilingual autobiographical memory: Experimental studies and clinical cases. Culture \& Psychology, 6(4), 387-417.

Smith, B. L., \& Tang, N. M. (2006). Different differences: Revelation and disclosure of social identity in the psychoanalytic situation. Psychoanalytic Quarterly, LXXV, 295-321.

Sue, D. W (2010). Microaggressions of everyday life. Hoboken, NJ: John Wiley. 
Swift, J. K., Callahan, J. L., Tompkins, K. A., Connor, D. R., \& Dunn, R. (2015). A delaydiscounting measure of preference for racial/ethnic matching in psychotherapy. Psychotherapy, 52(3), 315-320.

van der Kolk, B., Roth, S., Pelcovitz, D., Sunday, S., \& Spinazzola, J. (2005). Disorders of extreme stress: The empirical foundation of a complex adaptation to trauma. Journal of Traumatic Stress, 18(5), 389-399.

Vigoda Gonzales, N. (2017, October). The merits of integrating accelerated experiential dynamic psychotherapy and cultural competence strategies in the treatment of relational trauma: The case of "Rosa." Unpublished doctoral dissertation, Rutgers University, Piscataway, NJ.

Winnicott, D. W. (1960/1965). Ego distortion in terms of true and false self. In The maturational process and the facilitating environment (pp. 140-152). New York: International Universities Press. 
Table 1. Proposed ICD-11 diagnostic category for PTSD and Complex-PTSD

\begin{tabular}{|l|l|}
\hline Proposed ICD-11 categories & Core Diagnostic Features \\
\hline Post-traumatic stress disorder & $\begin{array}{l}\text { A disorder that develops following exposure to an } \\
\text { extremely threatening or horrific event or series of } \\
\text { events characterized by: 1) re-experiencing the } \\
\text { traumatic event(s) in the present in the form of } \\
\text { vivid intrusive memories accompanied by fear or } \\
\text { horror, flashbacks, or nightmares; } 2 \text { avoidance of } \\
\text { thoughts and memories of the event(s), or } \\
\text { avoidance of activities or situations reminiscent of } \\
\text { the event(s); and 3) a state of perceived current } \\
\text { threat in the form of excessive hypervigilance or } \\
\text { enhanced startle reactions. The symptoms must } \\
\text { last for at least several weeks and cause } \\
\text { significant impairment in functioning. }\end{array}$ \\
\hline Complex post-traumatic stress disorder & $\begin{array}{l}\text { A disorder which arises after exposure to a } \\
\text { stressor typically of an extreme or prolonged } \\
\text { nature and from which escape is difficult or } \\
\text { impossible. The disorder is characterized by the } \\
\text { core symptoms of PTSD as well as the } \\
\text { development of persistent and pervasive } \\
\text { impairments in affective, self and relational } \\
\text { functioning, including difficulties in emotion } \\
\text { regulation, beliefs about oneself as diminished, } \\
\text { defeated or worthless, and difficulties in } \\
\text { sustaining relationships. }\end{array}$ \\
\hline
\end{tabular}

(Maercker et al., 2013)

Table 2. Rosa's Scores: Hamilton Depression Rating Scale

\begin{tabular}{|c|c|}
\hline Pre-Treatment Score & Post-Treatment Score \\
\hline 30 & 8 \\
\hline
\end{tabular}

Score from the first 17 items

$0-7=$ Normal

8-13 = Mild Depression

14-18 = Moderate Depression

19-22 = Severe Depression

$\geq 23=$ Very Severe Depression 
Table 3. Trauma Symptom Inventory-2 Scales, Subscales, and Factors

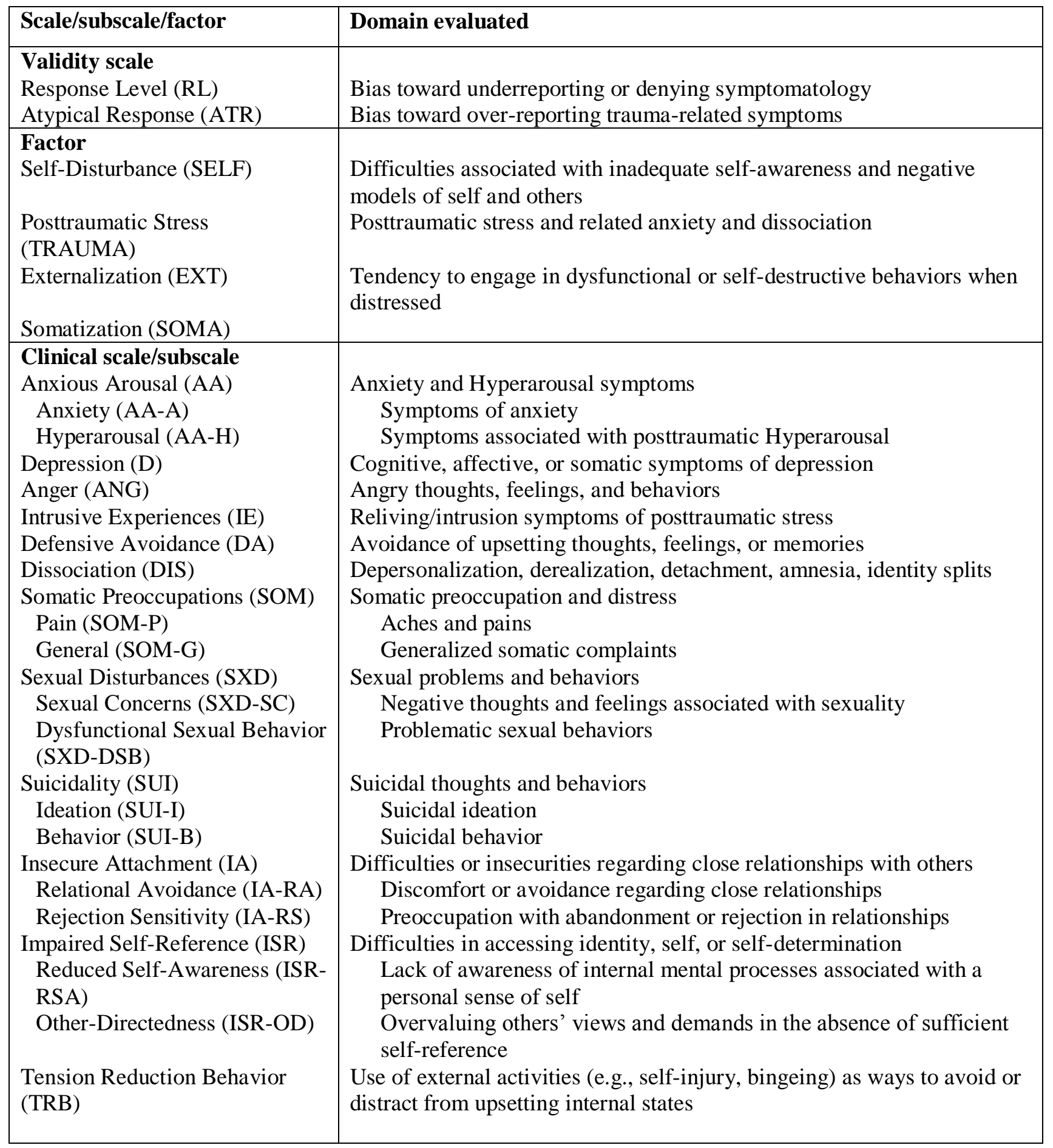

Briere, 2011, p. 2 
Table 4: Rosa's scores: Trauma Symptom Inventory-2

\begin{tabular}{|c|c|c|c|c|}
\hline Scale/subscale/factor & $\begin{array}{l}\text { "Pre" treatment } \\
\text { score ( } T \text { score })\end{array}$ & $\begin{array}{l}\text { "Post" treatment } \\
\text { score ( } T \text { score })\end{array}$ & $\begin{array}{l}\text { Change } \\
\text { score }\end{array}$ & $\begin{array}{l}\text { Reliable } \\
\text { Change } \\
\text { Scores** }\end{array}$ \\
\hline \multicolumn{5}{|l|}{ Validity scale } \\
\hline Response Level & 49 & 49 & 0 & 9 \\
\hline Atypical Response & 53 & 45 & -8 & 12 \\
\hline \multicolumn{5}{|l|}{ Factor } \\
\hline Self-Disturbance & 69 & 51 & $-18^{*}$ & 7 \\
\hline Posttraumatic Stress & 66 & 56 & $-10 *$ & 7 \\
\hline Externalization & 61 & 47 & $-14^{*}$ & 10 \\
\hline Somatization & 61 & 37 & $-24 *$ & 8 \\
\hline \multicolumn{5}{|l|}{ Clinical scale/subscale } \\
\hline Anxious Arousal & 69 & 56 & $-13^{*}$ & 7 \\
\hline Anxiety & 73 & 61 & $-12 *$ & 9 \\
\hline Hyperarousal & 63 & 50 & $-13^{*}$ & 10 \\
\hline Depression & 79 & 53 & $-26^{*}$ & 5 \\
\hline Anger & 54 & 47 & $-7 *$ & 7 \\
\hline Intrusive Experiences & 69 & 58 & $-11 *$ & 7 \\
\hline Defensive Avoidance & 65 & 60 & -5 & 6 \\
\hline Dissociation & 44 & 42 & -2 & 8 \\
\hline Somatic Preoccupations & 61 & 37 & $-24 *$ & 8 \\
\hline Pain & 67 & 41 & $-26^{*}$ & 10 \\
\hline General & 55 & 37 & $-18^{*}$ & 9 \\
\hline Sexual Disturbance & 45 & 45 & 0 & $9-10$ \\
\hline Sexual Concerns & 45 & 45 & 0 & 9 \\
\hline $\begin{array}{l}\text { Dysfunctional Sexual } \\
\text { Behavior }\end{array}$ & 47 & 47 & 0 & 11 \\
\hline Suicidality & 86 & 58 & $-28 *$ & 8 \\
\hline Ideation & 93 & 59 & $-34 *$ & 8 \\
\hline Behavior & 48 & 48 & 0 & 6 \\
\hline Insecure Attachment & 74 & 59 & $-15^{*}$ & 7 \\
\hline Relational Avoidance & 68 & 59 & $-9 *$ & 8 \\
\hline Rejection Sensitivity & 75 & 57 & $-18^{*}$ & 8 \\
\hline Impaired Self-Reference & 43 & 38 & -5 & 7 \\
\hline Reduced Self-Awareness & 46 & 42 & -4 & 10 \\
\hline Other-Directedness & 41 & 38 & -3 & 8 \\
\hline Tension Reduction Behavior & 54 & 41 & $-13^{*}$ & $11-12$ \\
\hline
\end{tabular}

* Difference is statistically significant via Jacobson and Truax's (1991) the Reliable Change Score.

** The Reliable change scores are $T$ scores based on Atkinson's (1991) and Naglieri, LeBuffe, and Pfeiffer's (1993) standard error of prediction, $S E p$ 
Table 5. Rosa's scores: OQ-45

\begin{tabular}{|l|l|l|l|l|c|}
\hline $\begin{array}{l}\text { Scale/ } \\
\text { Subscale }\end{array}$ & $\begin{array}{l}\text { Range } \\
\text { of } \\
\text { Scores }\end{array}$ & $\begin{array}{l}\text { Clinical } \\
\text { Cut-Off } \\
\text { Point }\end{array}$ & $\begin{array}{l}\text { Pre- } \\
\text { Treatment } \\
\text { Score at } \\
\text { Onset of } \\
\text { Treatment }\end{array}$ & $\begin{array}{l}\text { Post- } \\
\text { Treatment } \\
\text { Score at End } \\
\text { of } \\
\text { Treatment }\end{array}$ & $\begin{array}{l}\text { Change } \\
\text { between } \\
\text { Pre and } \\
\text { Post }\end{array}$ \\
\hline Total Score & $1-180$ & 63 & 102 & 43 & $59^{*}$ \\
\hline $\begin{array}{l}\text { Symptom } \\
\text { Distress Score }\end{array}$ & $0-100$ & 36 & 68 & 27 & $41^{*}$ \\
\hline $\begin{array}{l}\text { Interpersonal } \\
\text { Relations } \\
\text { Score }\end{array}$ & $0-44$ & 15 & 27 & 15 & $12^{*}$ \\
\hline $\begin{array}{l}\text { Social Role } \\
\text { Score }\end{array}$ & $0-36$ & 12 & 7 & 1 & 6 \\
\hline
\end{tabular}

* Change in scores is statistically significant via Jacobson and Truax's (1991) Reliable Change Index

Table 6. DSM-IV-TR Diagnosis at Onset and Termination

\begin{tabular}{|l|l|l|}
\hline & \multicolumn{1}{|c|}{ At onset } & \multicolumn{1}{c|}{ At termination } \\
\hline Axis I & $\begin{array}{l}\text { 296.33 Major Depressive } \\
\text { Disorder, recurrent, severe }\end{array}$ & $\begin{array}{l}\text { 296.35 Major Depressive } \\
\text { Disorder, recurrent, in partial } \\
\text { remission }\end{array}$ \\
\hline Axis II & None & None \\
\hline Axis III & Back Pain & None \\
\hline Axis IV & $\begin{array}{l}\text { Conflict with son; limited social } \\
\text { support; adjustment to life-cycle } \\
\text { (i.e., retirement) }\end{array}$ & Limited social support \\
\hline Axis V & GAF $=50$ & GAF $=75$ \\
\hline
\end{tabular}

